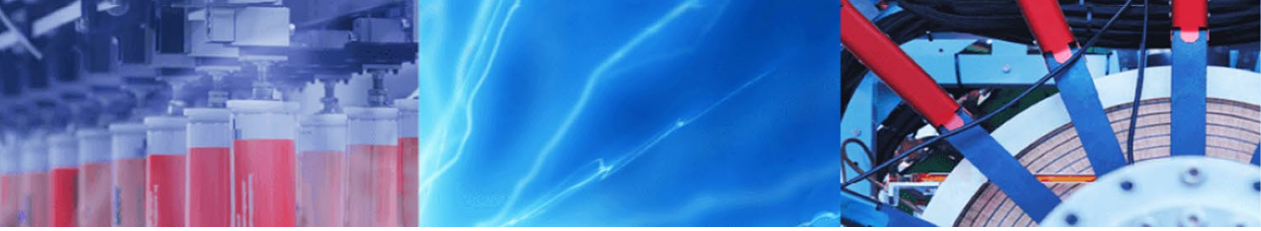

Research Article

\title{
Effect of the plate bondstress-slip property on the flexural strength of FRP Plated RC beams using a displacement-based approach
}

\author{
Mohamed El-Zeadani ${ }^{1} \cdot$ Raizal Saifulnaz Muhammad Rashid $^{1} \cdot$ Mugahed Yahya Hussein Amran ${ }^{2,3}$. \\ Mohamed Ibrahem Swi ${ }^{4}$
}

Received: 14 February 2020 / Accepted: 15 October 2020 / Published online: 29 October 2020

(c) Springer Nature Switzerland AG 2020

\begin{abstract}
This study presents the theoretical results of a displacement-based approach for CFRP plated RC beams while varying the bondstress-slip relationship of the plate to see the influence of this material property on the global behavior. The experimental programme included three ordinary and three plated RC beams that had similar dimensions and similar material properties. From the displacement-based analysis, it was shown that the theoretical and experimental results for the ordinary RC beams were almost identical. However, for the CFRP plated RC beams, it was shown that using a lineardescending bondstress-slip model for the FRP plate in the analysis underestimated the flexural capacity of the plated beam as the theoretical results were about $75 \%$ of the experimental values. Moreover, through a parametric study, it was shown that adding an ascending branch to the FRP plate's bondstress-slip property (e.g., using a bilinear bondstress-slip model) results in better correlation with the experimental values at service loads in comparison to using only a lineardescending branch without an ascending component. In addition, it was also shown that adding a frictional component to the bondstress-slip model of the FRP plate to allow the force in the plate to build up as debonding ensues gives closer results to the experimental values observed in the laboratory. The accurate simulation of the FRP plate's bondstress-slip material property was seen to greatly affect the plated member's capacity and ductility behavior.
\end{abstract}

Keywords Adhesively plated beam · FRP · Intermediate crack debonding · Displacement-based analysis · Partialinteraction · Bondstress-slip

\section{Introduction}

Enhancing the flexural capacity and service life of RC members through adhesively bonded fibre-reinforced polymer (FRP) plates/sheets has become a common practice recently [1, 2]. The analysis of such structures is typically carried out using a strain-based moment-curvature approach $[3,4]$, known as full-interaction, by which detachment of the plate can occur due to: (1) intermediate crack (IC) debonding [5-7]; (2) critical diagonal crack (CDC) debonding [8]; or (3) plate end (PE) debonding [9]. It is typical to design FRP plated RC structures for IC debonding first and then check for CDC and PE debonding [10]. As such, the full-interaction analysis is usually halted when the IC debonding strain is first observed in the plate. Following such design approach, debonding of the plate often occurs before the plate can achieve its full tensile strength and sometimes before the yielding of the steel rebars [11].

\footnotetext{
$\triangle$ Mohamed El-Zeadani, mohamed.elzeadani9595@gmail.com; Raizal Saifulnaz Muhammad Rashid, raizal@upm.edu.my; Mugahed Yahya Hussein Amran, m.amran@psau.edu.sa; Mohamed Ibrahem Swi, p97605@siswa.ukm.edu.my | 'Department of Civil Engineering, Universiti Putra Malaysia, 43400 Serdang, Malaysia. ${ }^{2}$ Department of Civil Engineering, Prince Sattam Bin Abdulaziz University, Alkharj 11942 , Saudi Arabia. ${ }^{3}$ Department of Civil Engineering, Faculty of Engineering and IT, Amran University, Quhal, 9677 Amran, Yemen. ${ }^{4}$ Faculty of Engineering \& Built Environment, Universiti Kebangsaan Malaysia, 43600 Bangi, Selangor, Malaysia.
} 
This has inspired several researchers to look into partialinteraction theory to predict the flexural strength of FRP plated members instead of the basic full-interaction methods. In essence, partial-interaction refers to the slip or sliding that occurs between steel bars or plate and surrounding concrete when a crack transverses the reinforcement. Furthermore, partial-interaction is not only restricted to sliding between the reinforcement and concrete, but can account for sliding between two concrete surfaces as well, and this is known as shear friction [12]. To quantify the force in the reinforcement due to sliding against the adjacent concrete, researchers carried out tension stiffening analysis of concrete prisms, and both numerical methods [13] and closed-form solutions [14] were developed. In addition to that, shear friction theory was utilized to determine the compressive forces in concrete while accounting for both the elastic and inelastic deformations caused by sliding of the concrete wedge $[15,16]$. To link the tensile and compression regions of the RC structure, a momentrotation analysis at an RC hinge was first performed [17]; and later moment-rotation analysis of RC beam segments were presented as well which accounted for the formation of multiple cracks [18].

Quantifying the moment-rotation relationship of RC segments allowed researchers to come up with mechanics-based solutions to calculate the mid-span deflection of RC beams [19, 20], non-prismatic RC beams [21] and FRP plated RC beams [22]. The research on partialinteraction design of RC structures progressed such that displacement-based mechanics solutions for predicting the flexural capacity of FRP plated RC beams were presented $[11,23,24]$. The displacement-based approach considered the plate's IC debonding mechanism and this is illustrated by the FRP plated prism depicted in Fig. 1. In such case, failure does not occur when the loaded end of the plate achieves the IC debonding strain as shown in Fig. 1a; instead, the plate continues to extend, allowing for the propagation of debonding in the plate as shown in Fig. 1 b. Failure through IC debonding ultimately occurs when the entire plate undergoes debonding (Fig. 1c). Similarly, when the moment in the FRP plated beam in Fig. 2 reaches $M_{1 C}$, the force in the plate becomes $P_{I C}$ which induces the initiation of $\mathrm{IC}$ debonding as in Fig. 1 a. In case the moment is increased further, say to $M_{1}$ in Fig. 2a, part of the plate debonds as in Fig. $1 \mathrm{~b}$ and the elongation within the debonded region becomes ${ }_{\max }{ }_{{ }_{I C}} L_{d b-p}$. Within this debonded region, the plate is not bonded to the concrete surface and acts as a passively prestressed tendon exerting a force $\mathrm{P}_{\mathrm{IC}}$ on the RC member at the position of the plate [11]. This theoretical novel approach, presented by Oehlers et al. [11], allowed for the plated beam to carry greater loads, but was not verified against experimental results.

In addition, numerous researchers have investigated the bondstress-slip relationship for externally bonded plates [25-27] and many more have tried to measure the FRP-to-concrete interface bond strength [28-30]. In doing so, researchers have quantified the FRP-to-concrete bond characteristics using double-shear or single-shear pull-push tests, or beam tests [29]. In all of these tests, the concrete prism length is usually marginally larger than the plate's effective length (or critical length) and typical bondstress-slip relationships are depicted in Fig. 3. Given that the slip at maximum bondstress, 1, for FRP plated beams is much smaller than the maximum debonding slip, max it is common to simplify the analysis by adopting
Fig. 1 IC debonding mechanism [11] (a)

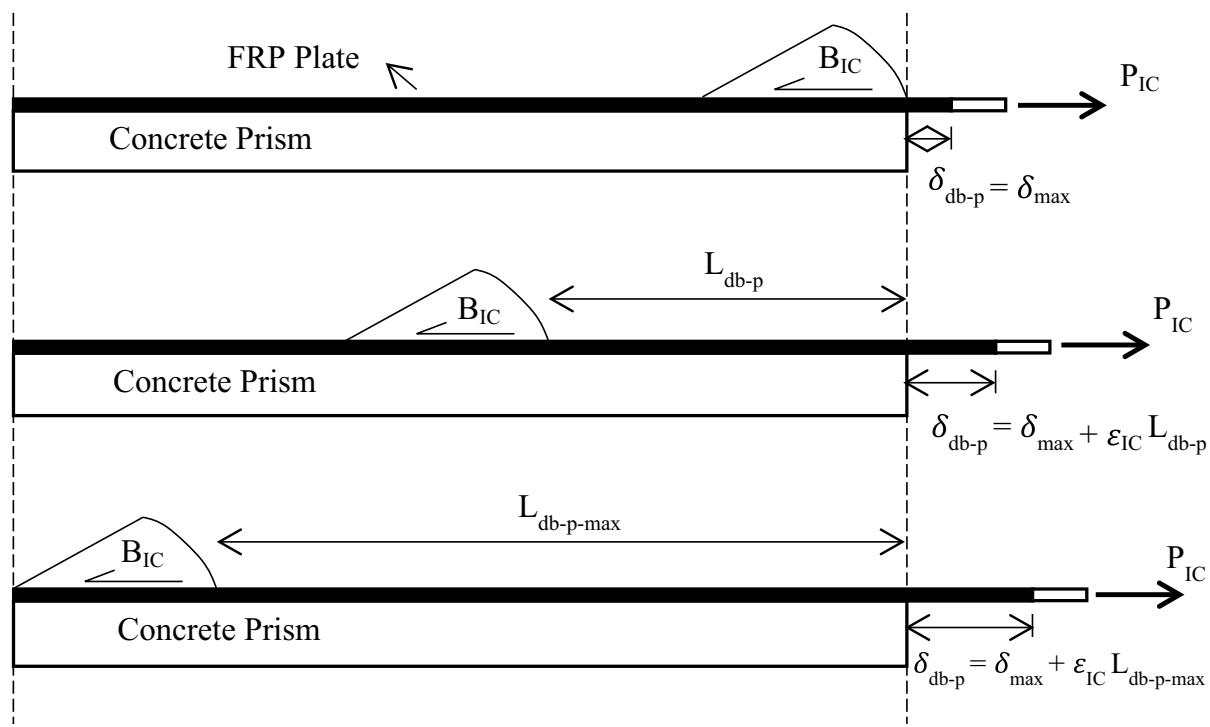


Fig. 2 Debonding mechanism of a symmetrically loaded FRP plated member [11]

(a)

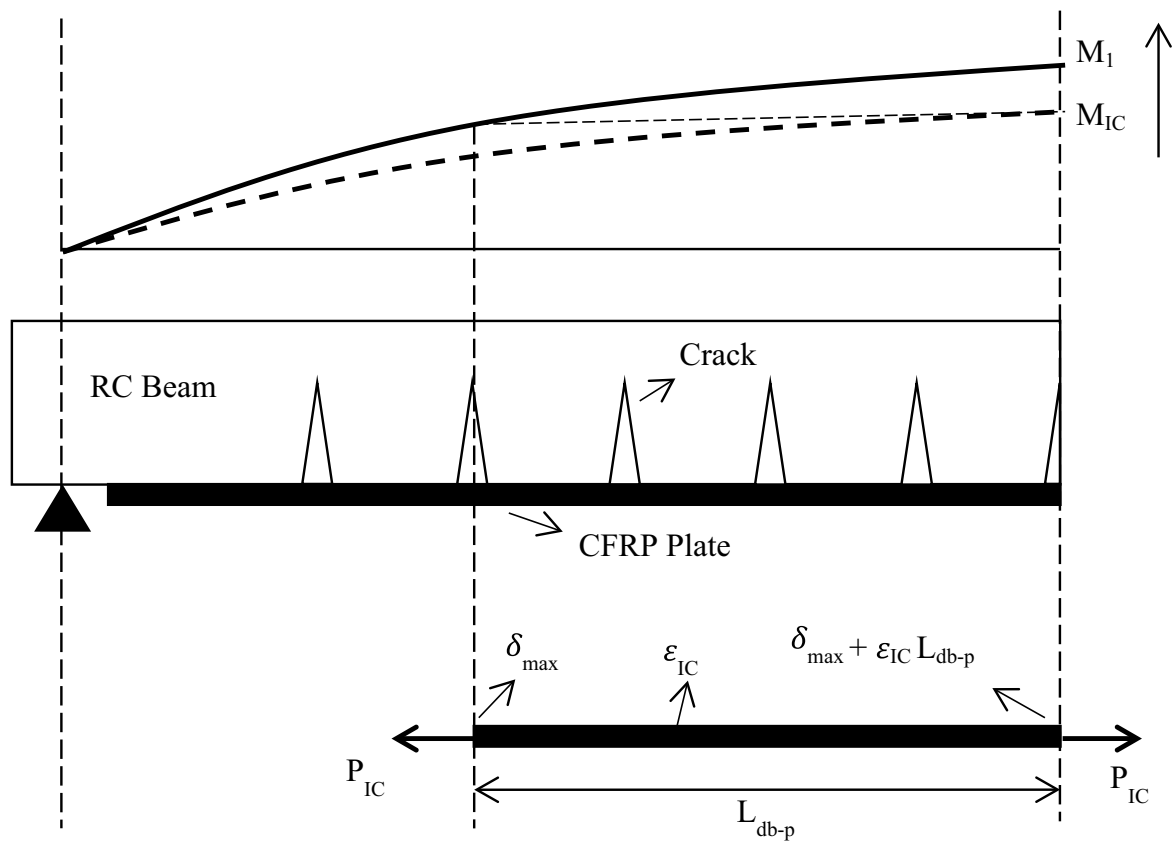

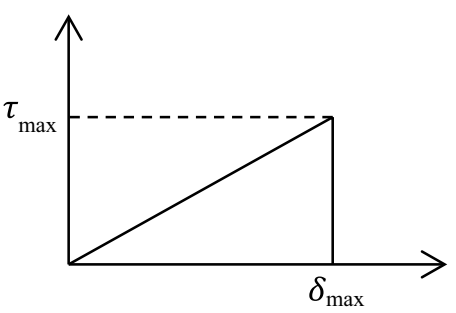

(a)

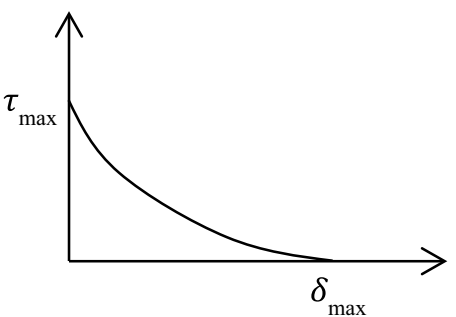

(d)

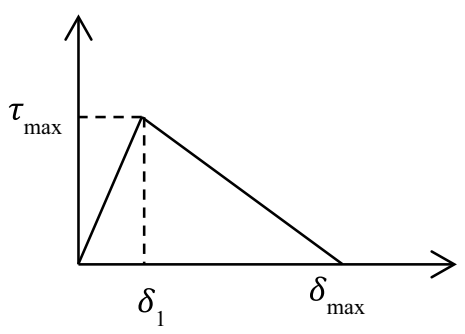

(b)

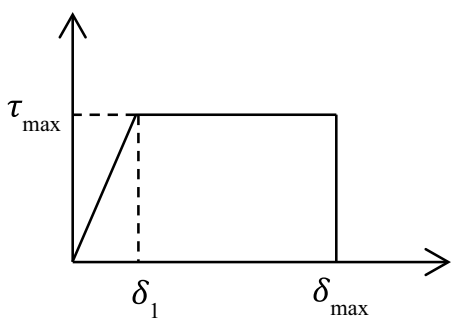

(e)

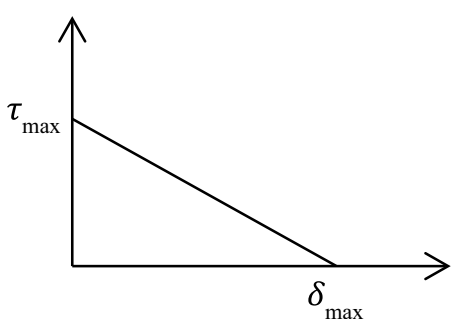

(c)

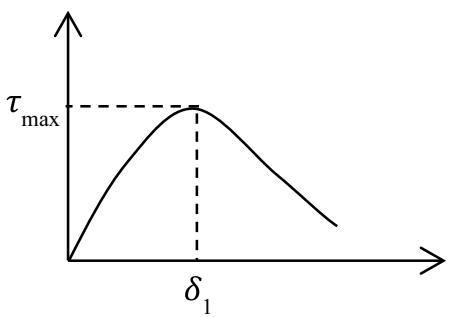

(f)

Fig. 3 Different bondstress-slip models

a linear-descending relationship as shown in Fig. 3c [31], especially when the ultimate capacity of the RC beam is required.

The bondstress-slip models proposed by previous researchers hardly have a residual frictional component; however, Zhang and Smith [32] state that a residual friction (or shear) component, $f$, as shown in Fig. 4, may develop in the FRP-to-concrete interface when either: (a) the bonded length of the plate in the concrete prism is more than the plate's critical length; (b) the plate length in flexural members is more than the pate's critical length; or (c) anchorage devices are installed in the plate. Henceforth, for FRP plated RC beams, a frictional component may indeed form in the plate as it undergoes deformation due to loading as most plated RC members have lengths in excess of the critical length of the plate. Therefore, the objectives of this publication are: (a) to compare the results of the theoretical displacement-based approach with experimental results; (b) to determine the effect of the bondstress-slip relationship on the global behavior of the FRP plated beam 


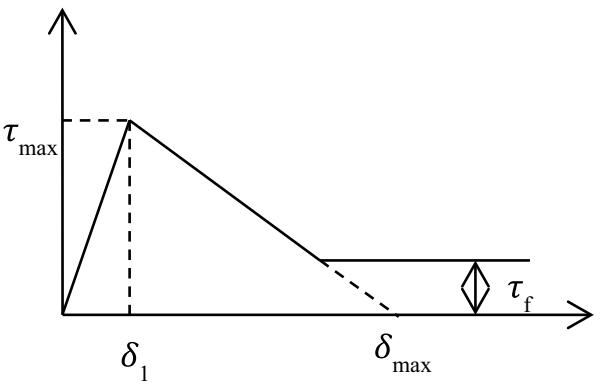

Fig. 4 Bondstress-slip model with frictional component [32]

using a displacement-based approach, and to see whether a frictional component develops in the FRP plate as it undergoes deformation prior to complete debonding. As such, the related segmental analysis and displacement-based analysis of the FRP plated member are presented first. After that, the experimental programme is given which includes three ordinary RC beams and three CFRP plated RC beams. Next, the results of the displacement-based analysis are presented and compared with the experimental values. Finally, a parametric study is given to show the effect of altering the bondstress-slip property on the global behavior of the FRP plated member (e.g., adding a frictional component or adding an ascending branch).

\section{Segmental analysis}

In the ensuing segmental analysis, the concrete full stressstrain relationship was determined using Popovics [33] expression as follows;

$\frac{\sigma_{a x}}{f_{c c}}=\frac{\left[\frac{\left(\varepsilon_{a x}\right)_{200}}{\varepsilon_{c c}}\right] r}{r-1+\left[\frac{\left(\varepsilon_{a x}\right)_{200}}{\varepsilon_{c c}}\right]^{r}}$

where ${ }_{a x}$ is the axial stress, $\left({ }_{a x}\right)_{200}$ is the $200 \mathrm{~mm}$ cylinder axial strain, $\mathrm{f}_{\mathrm{cc}}$ is the confined concrete peak stress, ${ }_{c c}$ is the confined concrete strain at peak stress, and $r$ is a ductility factor. Both $\mathrm{f}_{\mathrm{cc}}$ and ${ }_{\mathrm{cc}}$, together with $\mathrm{r}$ in Eq. (1) can be determined as follows [16];

$f_{c c}=f_{c o}\left[1+3.65\left(\frac{\sigma_{c o n}}{f_{c o}}\right)^{0.82}\right]$

$\varepsilon_{c c}=\varepsilon_{c o}\left[1+14.74\left(\frac{\sigma_{c o n}}{f_{c o}}\right)^{1.03}\right]$
$r=\frac{E_{c}}{E_{c}-\frac{f_{c c}}{\varepsilon_{c c}}}$

where $\mathrm{f}_{\text {co }}$ is the unconfined concrete peak stress, co is the unconfined concrete strain at peak stress, con is the confinement stress, usually provided by the stirrups, and $\mathrm{E}_{c}$ is the concrete elastic modulus. Chen et al. [15] give ${ }_{\text {co }}$ as;

$\varepsilon_{c o}=4.76 \times 10^{-6} f_{c o}+2.13 \times 10^{-3}$

The confinement stress, con, can be calculated using the following expression [17];

$\sigma_{\text {con }}=\frac{n\left(f_{y-\text { link }}\right)\left(A_{\text {link }}\right)}{b\left(S_{\text {link }}\right)}$

where $f_{y \text {-link }}$ is the steel stirrups' yield stress, $A_{\text {link }}$ is the cross-sectional area of the steel stirrups, $\mathrm{n}$ is the number of legs in the steel stirrups, $S_{\text {link }}$ is the spacing between different stirrups, and $b$ is the width of the beam. In addition, the $\mathrm{ACl}$ code [34] give $\mathrm{E}_{\mathrm{c}}$ as;

$E_{c}=3320 \sqrt{f_{c o}}+6900$

where $f_{c o}$ in Eqs. (5) and (7) is in MPa. The size and shape effect of the concrete segment in compression, as well as the formation of the concrete wedge, were accounted for following Chen et al. [15] and Chen et al. [16] method. For instance, the size-dependent axial global strain, axgl, was taken as;

$\varepsilon_{\text {axgl }}=\left[\left(\varepsilon_{a x}\right)_{200}-\varepsilon_{\text {mat }}\right] \frac{100}{L_{\text {def }}}+\varepsilon_{\text {mat }}$

where $\varepsilon_{\text {mat }}$ is the elastic material strain and $L_{\text {def }}$ is half the segment length.

The reinforcement steel stress-strain relationship was idealized by the model illustrated in Fig. 5a [20]. Such model accounts for the elastic response of the reinforcement and the post yield response as well. Moreover, the stress-strain response depicted in Fig. 5b was used to represent the constitutive relationship for the CFRP plate $[3,22]$.

Furthermore, the bondstress-slip model presented by Haskett et al. [13] and depicted in Fig. 6a was adopted for the reinforcement steel to represent local deformations. As for the CFRP plate, the linear-descending bondstressslip model presented by Seracino et al. [31] and shown in Fig. $6 \mathrm{~b}$ was used in the analysis. Generic expressions for the maximum slip, max $^{\prime}$ and maximum bondstress, $\max ^{\prime}$ for a given plate configuration are given as follows [31]; 
$\delta_{\max }=\frac{0.976 \varphi_{f}^{0.526}}{0.802+0.078 \varphi_{f}}$

$\tau_{\max }=\left(0.802+0.078 \varphi_{f}\right) f_{c}^{0.6}$

where

$\varphi_{f}=\frac{t_{d}}{2 t_{b}+b_{p}}$

and $t_{d}$ and $t_{b}$ in Eq. (11) can be taken as $1 \mathrm{~mm}[31]$, and $b_{p}$ is the width of the plate.

\subsection{Uncracked segmental analysis}

Initially, an uncracked segmental analysis takes place as shown in Fig. 7 which is basically a full-interaction analysis. Half the segment is rotated by an angle as in Fig. 7, and the depth of the neutral axis, $d_{N A}$, is first assumed. Next, the segment's curvature, , can be determined as follows;

$\chi=\frac{\theta}{L_{\text {def }}}$

where $L_{\text {def }}$ is half the segment length as illustrated in Fig. 7, and angle is in radians. Having determined the curvature of the segment, the strain in the furthest compression and tensile fibres can be calculated accordingly as follows;
Fig. 5 Idealized stress-strain relationship: (a) steel rebars; (b) FRP plate

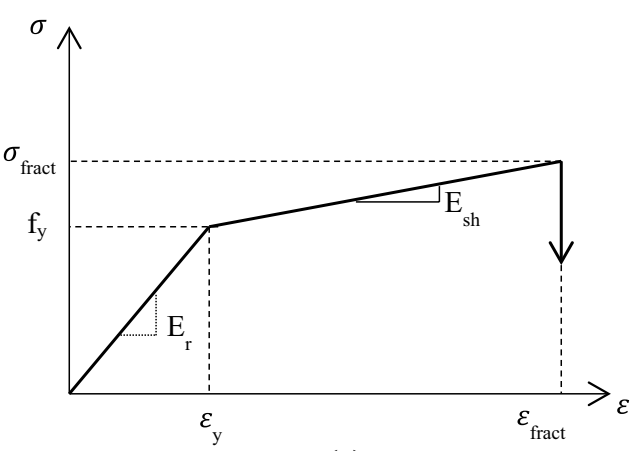

(a)

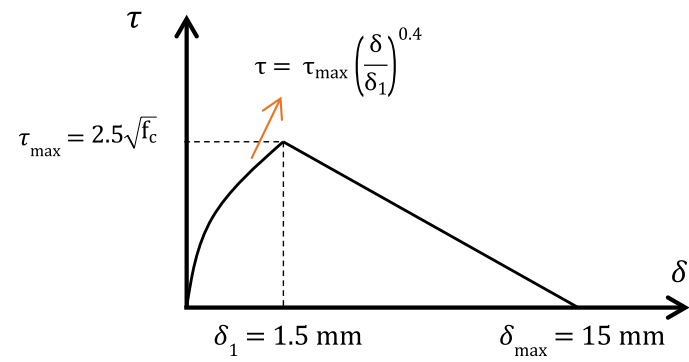

(a)

Fig. 6 Bondstress-slip characteristic: (a) steel rebars; (b) FRP plate

Fig. 7 Uncracked segmental analysis

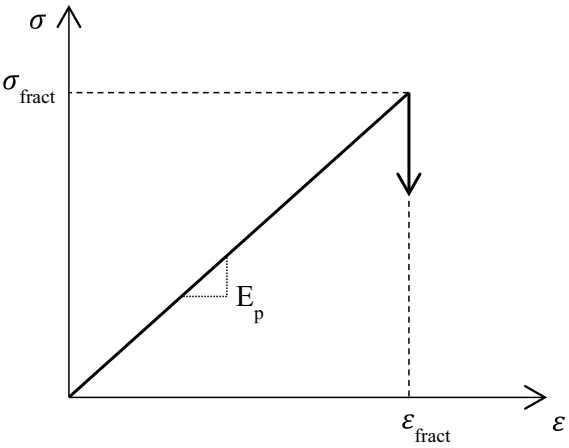

(b)

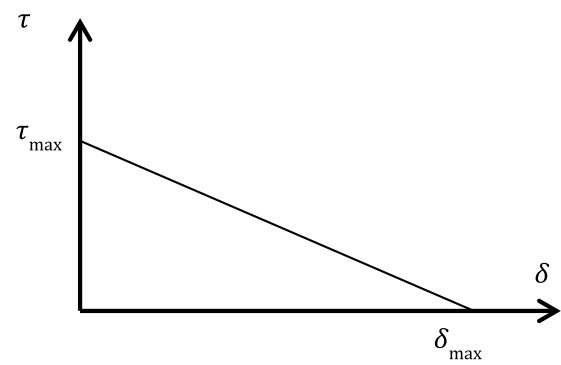

(b)

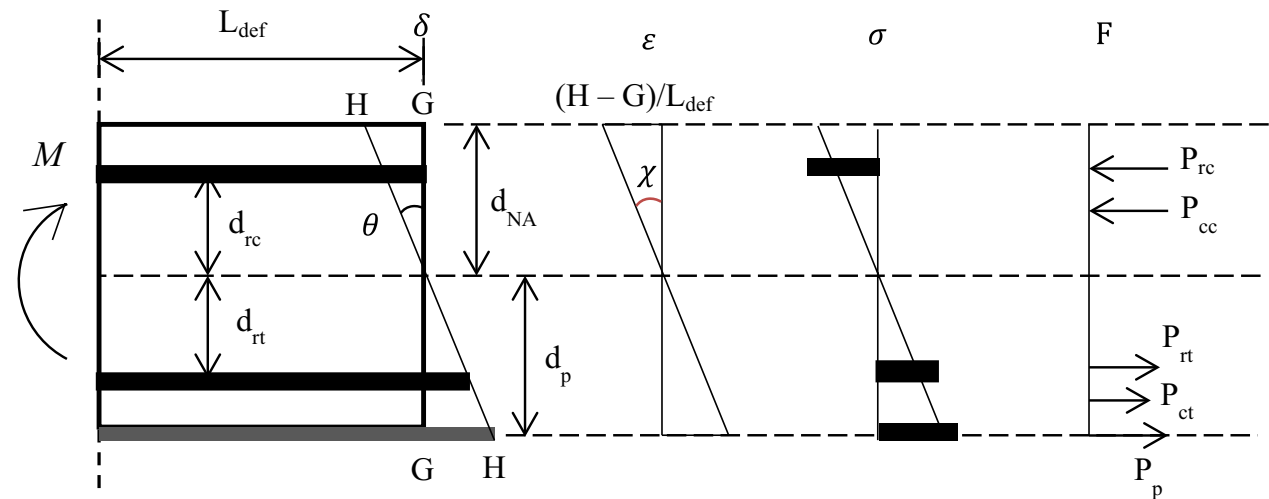

(a) (b) (d) (e) 
$\varepsilon_{c-c}=\chi d_{N A}$

$\varepsilon_{c-t}=\chi\left(h-d_{N A}\right)$

Similarly, the strain in in the compression rebars, tension rebars, and FRP plate can be determined as follows;

$\varepsilon_{r c}=\chi d_{r c}$

$\varepsilon_{r t}=\chi d_{r t}$

$\varepsilon_{\mathrm{p}}=\chi \mathrm{d}_{\mathrm{p}}$

where $d_{r c^{\prime}} d_{r t^{\prime}}$ and $d_{p}$ are as shown in Fig. 7.

The stress distribution in the uncracked segment is illustrated in Fig. 7d. A triangular stress distribution initially governs the concrete in compression and tension as shown. From the concrete stress diagram, the concrete compressive force, $\mathrm{P}_{\mathrm{cc}{ }^{\prime}}$ and concrete tensile force, $\mathrm{P}_{\mathrm{ct}^{\prime}}$ can be derived accordingly. $P_{c c}$ acts at $1 / 3 d_{N A}$ from the top of the segment while $P_{c t}$ acts at $1 / 3\left(h-d_{N A}\right)$ from the bottom of the segment. Moreover, as the strains in the reinforcement bars and FRP plate have already been determined, the reinforcement compressive force, $P_{r c}$, the reinforcement tensile force, $\mathrm{P}_{\mathrm{rt}}$, and the FRP plate force, $\mathrm{P}_{\mathrm{p}^{\prime}}$ can be determined from their material properties. Having determined all the forces acting along the segment, the goal is to find the depth $d_{N A}$ that would ensure force equilibrium for a given rotation, after that, the moment of the segment, M, can be calculated. Having done so, the rotation , is changed and the new moment $M$ is determined. The above analysis is continued until a tensile crack forms in the segment.

\subsection{Single crack segmental analysis}

At this point, the analysis starts with a single crack segmental analysis shown by the initial crack in Fig. 8. The closed-form solution for the force $P_{r t}$ following a singlecrack segmental analysis is given as follows [14];

$P_{r t}=A_{r t} E_{r t} \sqrt{\frac{2 \lambda_{2} \Delta_{r t}^{1+\varphi}}{1+\varphi}}$

where

$\lambda_{2}=\frac{\beta_{2} \tau_{\max }}{\delta_{1}^{\varphi}}$

$\beta_{2}=\frac{L_{p}}{A_{r t}}\left(\frac{1}{E_{r t}}+\frac{A_{r t}}{E_{c} A_{c}}\right)$

$E_{r t}$ and $A_{r t}$ in Eq. (18) are the Young's modulus and the cross-sectional area of the tensile reinforcement, $\varphi$ is a factor equal to $0.4, L_{p}$ is the sum of the perimeter of the tensile reinforcement, and $A_{c}$ is the area of the concrete prism taken as $(b \times 2 c)$ where $c$ is the measurement from the middle of the tensile reinforcement to the bottom tensile fibre. Equation (18) applies while the reinforcement is still elastic; however, when the reinforcement yields, the closed-form solution is given as follows [20];

$P_{r t}=A_{r t} E_{s h} \sqrt{\frac{2 \lambda_{s h}\left(\Delta_{r t}-\Delta_{y}\right)^{1+\varphi}}{1+\varphi}}+A_{r t} f_{y}$

where
Fig. 8 IC debonding segmental analysis

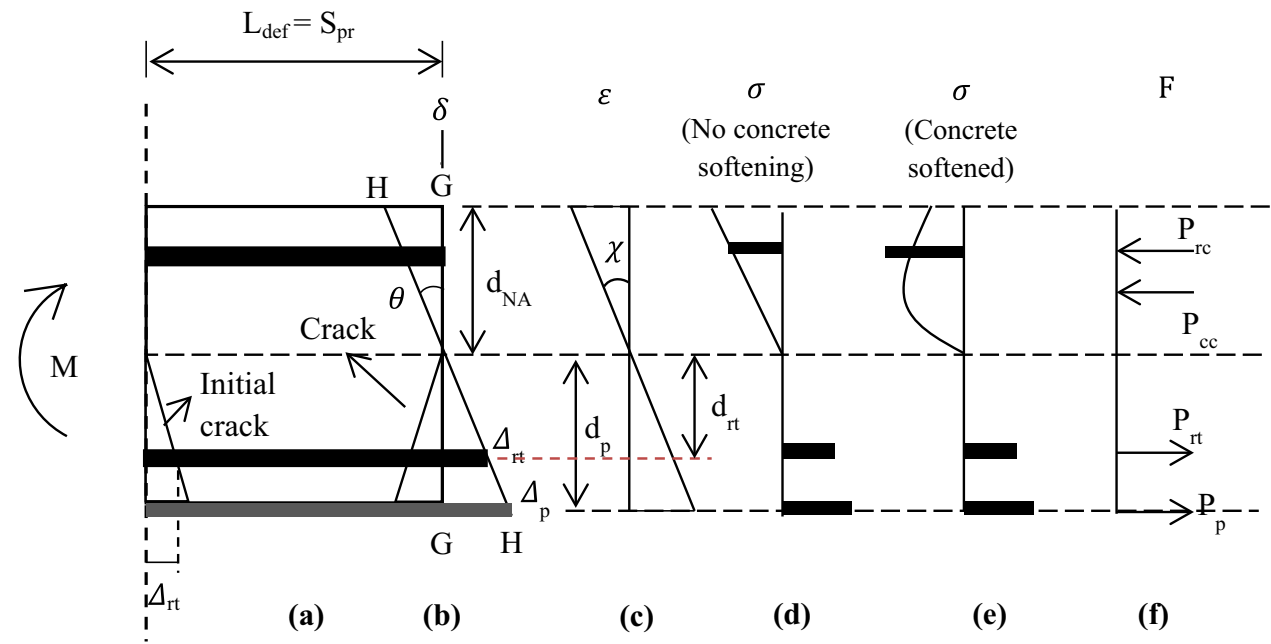

SN Applied Sciences 
$\lambda_{s h}=\frac{\beta_{s h} \tau_{\max }}{\delta_{1}^{\varphi}}$

$\beta_{s h}=\frac{L_{p}}{A_{r t}}\left(\frac{1}{E_{s h}}+\frac{A_{r t}}{E_{c} A_{c}}\right)$

$f_{y}$ is the steel yielding stress, $E_{s h}$ is the strain-hardening modulus as shown in Fig. $5 a^{a}$ and $_{y}$ in Eq. (21) is given by;

$\frac{\lambda_{2} \Delta_{y}{ }^{1+\varphi}}{1+\varphi}=0.5\left(\frac{f_{y}}{E_{r t}}\right)^{2}$

As for the force in the FRP plate, following a lineardescending bondstress-slip model as in Fig. 6b, the closed-form solution is given by [14];

$P_{p}=A_{p} E_{p} \lambda_{3} \delta_{\max } \sin \left[\arccos \left[\frac{\delta_{\max }-\Delta_{p}}{\delta_{\max }}\right]\right]$

where

$\lambda_{3}=\sqrt{\frac{\tau_{\max }}{\delta_{\max }} \beta_{2}}$

and $E_{p}$ and $A_{p}$ are the modulus of elasticity and crosssectional area of the FRP plate. The concrete compressive force, $P_{c c}$ in Fig. $8 f$ can be determined by taking the area under the stress diagram in Fig. 8e. Equation (1) can be used to plot the concrete stress diagram while considering the softening branch as well, while Eq. (8) can be used to account for the size of the concrete segment. As before, force equilibrium is first sought after by fixing the rotation and changing $d_{N A}$ until the summation of forces is equal zero. After that, the moment of the segment is determined. The same procedure is repeated again with a different segment rotation and the resulting moment is subsequently recorded.

\subsection{Multiple crack segmental analysis}

As the tensile reinforcements' force builds up, further flexural cracks form at distance $S_{\text {pr }}$ from the original crack, and the behavior reverts to that of a multiple crack segmental analysis as illustrated in Fig. 8. The distance $\mathrm{S}_{\mathrm{pr}}$ can be calculated as follows [14];

$S_{p r}=\left[\frac{(1+\varphi) f_{c t} A_{c} \delta_{1}^{\varphi}}{\tau_{\text {max }} L_{p}\left(\sqrt{2 C_{9}}\right)^{\varphi}}\right]^{\frac{1}{1+\varphi}}$

where
$C_{9}-\frac{\sqrt{2 C_{9}} f_{c t} A_{c} \lambda_{2} \delta_{1}^{\varphi}}{\tau_{\max } L_{p}}=-0.5\left(\frac{f_{c t}}{E_{c}}+\frac{f_{c t} A_{c}}{A_{r t} E_{r t}}\right)^{2}$

and $f_{c t}$ is the concrete tensile strength. The closed-form solution for the tensile reinforcement force, $\mathrm{P}_{\mathrm{rt}}$, following the CEB-FIP bondstress-slip ascending branch (Fig. 5a), when multiple cracks form prior to and after yielding of the reinforcement are given as follows [20];

$P_{r t}=A_{r t} E_{r t} \sqrt{\frac{2 \lambda_{2} \Delta_{r t}{ }^{1+\varphi}}{1+\varphi}+\left(\frac{\Delta_{r t}}{S_{s}}\right)^{2}}$

$P_{r t}=A_{r t} E_{s h} \sqrt{\frac{2 \lambda_{y}\left(\Delta_{r t}-\Delta_{y_{\_} p}\right)^{1+\varphi}}{1+\varphi}+\left(\frac{\Delta_{r t}-\Delta_{y \_}}{S_{s}}\right)^{2}}+A_{r t} f_{y}$

where $\Delta_{y_{-} p}$ can be determined from the following expression,

$\frac{\lambda_{2} \Delta_{y \_p}^{1+\varphi}}{1+\varphi}+0.5\left(\frac{\Delta_{y \_p}}{S_{s}}\right)^{2}=0.5\left(\frac{f_{y}}{E_{r t}}\right)^{2}$

and $S_{s}$ is equal to $S_{p r} / 2$. As for the FRP plate, a single-crack analysis dominates since the behavior of EB FRP plates ultimately revert back to single crack analysis. The closed-form solution for the FRP plate is given by Eq. (25); however, the slip of the plate is taken as the entire slip across $L_{\text {def }}$, which is $2_{p}$ in Fig. 8a. As for the concrete in compression, $P_{c c}$ is determined as before while considering the size of the segment and softening of the concrete in compression. For each rotation, the resulting moment is determined, and the analysis is continued until a rotation causes the slip of the plate, $p$, to reach max. The corresponding moment when equals $_{\text {max }}$ is the moment that causes the plate's IC debonding and is commonly known to as the IC debonding moment, $\mathrm{M}_{\mathrm{IC}}$. After this moment in the beam is achieved, the plate is assumed to be detached from the concrete surface [11], and the analysis is continued following a passively prestressed segmental analysis as depicted in Fig. 9.

\subsection{Passively prestressed segmental analysis}

The passively prestressed segment is subjected to $\mathrm{P}_{\mathrm{IC}}$ at plate's level. In case this force is applied first prior to any deformation, this will cause the displacement A-A shown in

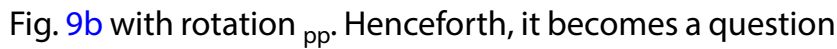
of determining the resultant force $P_{R C}\left(P_{r c}+P_{c c}-P_{r t}-P_{c t}\right)$ at the plate's level that is equivalent to $P_{I C}$ and a zero moment at the same level. In case the concrete in tension cracks, then $\mathrm{P}_{\mathrm{rt}}$ in Fig. $9 \mathrm{c}$ will have to be determined using partial-interaction. 
Fig. 9 Passively prestressed segmental analysis

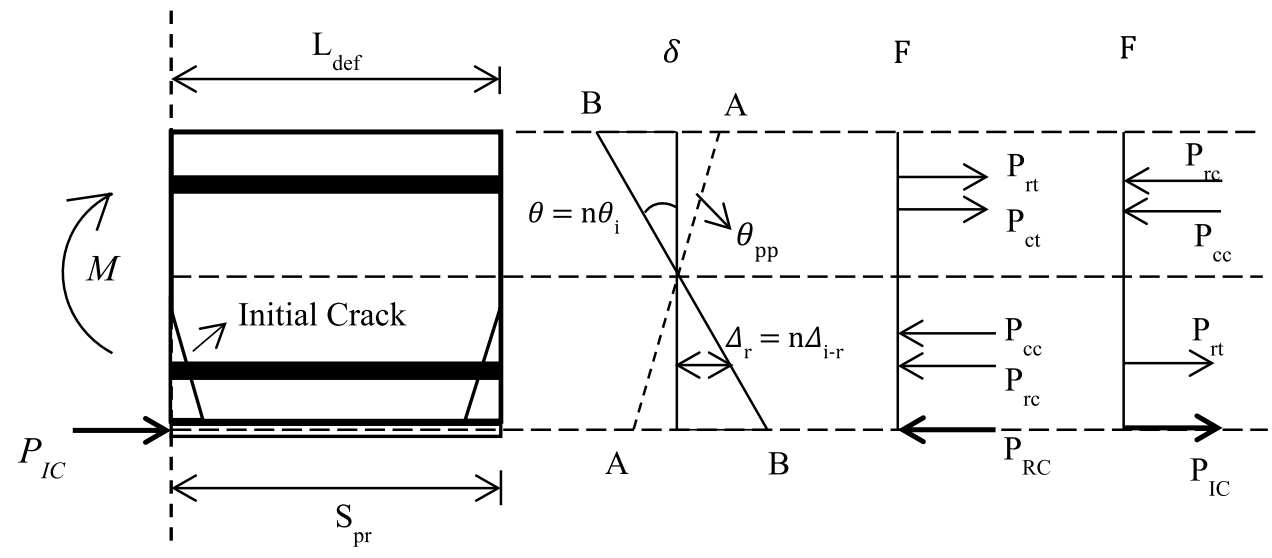

(a)

(c)

(d)
The passively prestressed segmental analysis is continued by applying a moment $M$ that causes the displacement of the segment to change to that of line B-B in Fig. 9b. At this stage, a single crack shown as the initial crack in Fig. 9a takes place. The force profile is now given by that in Fig. $9 \mathrm{~d}$ and the resultant of the forces should be equivalent to $\mathrm{P}_{\mathrm{I}}$; after which, the segment's moment can be measured at the plate's level. Once $P_{r t}$ reaches the force to cause primary cracks, $P_{p r}$ another crack forms at $S_{p r}$ from the former crack as depicted in Fig. 9a, and the force in the steel rebars is now governed by a multiple crack analysis. Again, the section is rotated until the resultant force, $\mathrm{P}_{\mathrm{RC}}$, is equivalent to the $\mathrm{IC}$ debonding force, $\mathrm{P}_{\mathrm{I} C}$, after which the moment at the level of the plate can be calculated.

\section{Displacement-based flexural capacity of FRP plated RC beams}

The moment-rotation (M-) analysis described above can be utilized to plot the $M$ - relationship of a passively prestressed segment as shown in Fig. 10a. Using the M- plot, the moment-curvature ( $M-$-) relationship can be calculated by dividing the rotation by the concrete segment's halflength, $L_{\text {def }}$ as illustrated in Fig. 10b. Also, the concrete strain at plate's level, ${ }_{\mathrm{RC}}$ (the product of the segment's curvature and the plate's depth from the neutral axis, $d_{p}$ ) can be plotted against the moment as shown in Fig. 10c. As the $\mathrm{M}$ - in the Fig. 10 is derived from a passively prestressed segment as in Fig. 9, a passively prestressed rotation exists as shown in in Figs. $9 b$ and 10 when $M=0$. This arises due to the passively prestressed force $\mathrm{P}_{\mathrm{I}}$, which requires rotation $_{\mathrm{pp}}$ for the segment to be in equilibrium.

Figure $11 \mathrm{c}$ shows the plate displacement over the halflength of a symmetrically loaded adhesively plated beam. This displacement of the plate can be calculated as [11];

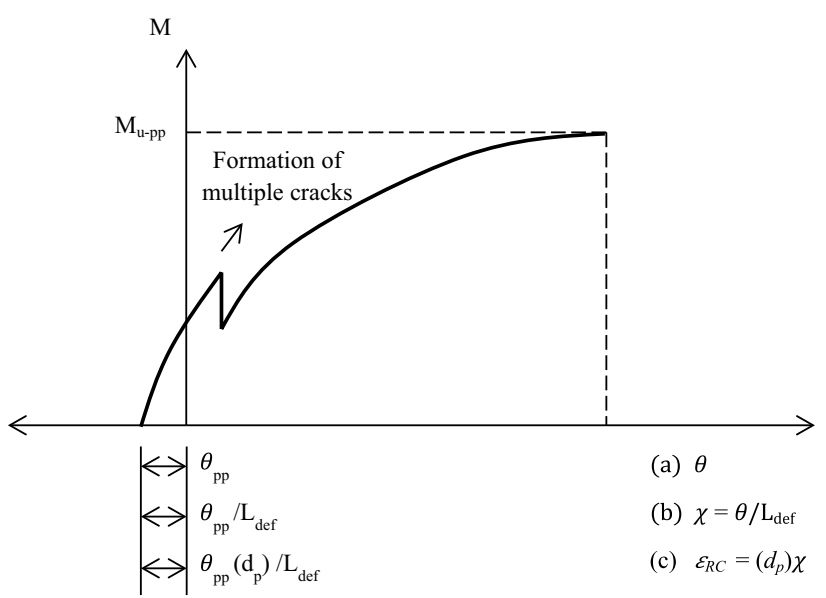

Fig. 10 Moment relationship of a passively prestressed segment: (a) ; (b) ; (c) ${ }_{\mathrm{RC}}$ (a)

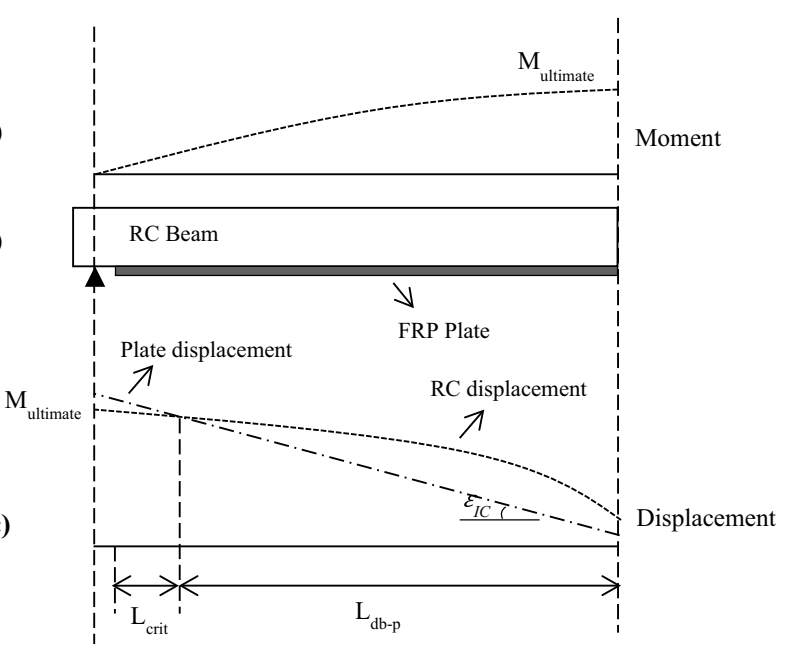

Fig. 11 FRP plated beam flexural capacity 
$\delta_{\mathrm{db}-\mathrm{p}}=\delta_{\max }+\varepsilon_{\mathrm{lC}} \mathrm{L}_{\mathrm{db}-\mathrm{p}}$

where $\varepsilon_{\mathrm{IC}}$ is the IC debonding strain, and $\mathrm{L}_{\mathrm{db}-\mathrm{p}}$ is the debonded length of the plate. In addition, Fig. 11c illustrates the concrete displacement at the plate's level for a given applied moment, $M$, on the beam. The concrete displacement can be given by [11];

$\delta_{\mathrm{db}-\mathrm{RC}}=\int_{0}^{\mathrm{L}_{\mathrm{db}}} \varepsilon_{\mathrm{RC}}$

where $_{\mathrm{RC}}$ can be determined from Fig. 10c. The ultimate moment $\left(M_{\text {ultimate }}\right)$ of the adhesively plated beams is achieved when the plate's displacement, given by Eq. (32), equals the concrete displacement at the plate's level, given by Eq. (33), at distance $L_{\text {crit }}$ from the plate end, satisfying the conditions of displacement compatibility at the plate's level (Fig. 11C). The critical length of the plate, $L_{\text {crit' }}$ can be calculated as follows [31];

$\mathrm{L}_{\text {crit }}=\frac{\pi}{2 \lambda}$

where

$\lambda^{2}=\frac{\tau_{\max } L_{p}}{\delta_{\max } E_{p} A_{p}}$

\section{Experimental programme}

A total of six $\mathrm{RC}$ beam specimens were considered here, three of those were carbon fibre-reinforced polymer (CFRP) plated RC beams tested by El-Zeadani et al. [22].
The remaining three beam specimens, tested by ElZeadani et al. [20], were identical to the plated RC beams but without the CFRP plates to ensure the validity of the mechanics-based solution in the absence of the FRP plate. A brief description of the beam specimens, materials and test setup is given below.

\subsection{Beam details}

The adhesively plated beams (CFRP-B1, CFRP-B2 and CFRPB3), illustrated in Fig. 12, had a total span of $3600 \mathrm{~mm}$ and a $3500 \mathrm{~mm}$ span between the supports. The tension face CFRP plate had a total length of $3250 \mathrm{~mm}$, a thickness of $1.2 \mathrm{~mm}$ and a width of $50 \mathrm{~mm}$. Furthermore, the beams had $16 \mathrm{~mm}$ and $12 \mathrm{~mm}$ diameter tensile and compression steel reinforcement, respectively, as illustrated in Fig. 12a. Also, the plated beams had $8 \mathrm{~mm}$ diameter mild steel shear links spaced at $150 \mathrm{~mm}$. As for the unplated RC beams (RC-B1, RC-B2 and RC-B3), they had similar properties to the adhesively plated ones except for the fact that no CFRP plate was attached to their tension face and their details are shown in Fig. 13.

\subsection{Materials}

All six beam specimens were casted on the same day and had similar material properties. The $150 \times 150 \mathrm{~mm} 28$ th day mean concrete cube compressive strength was $26.3 \mathrm{MPa}$. The $150 \times 300 \mathrm{~mm}$ diameter and the $100 \times 200 \mathrm{~mm}$ diameter mean cylinder compressive strengths were $20.5 \mathrm{MPa}$ and $22.7 \mathrm{MPa}$, respectively. Furthermore, Table 1 gives the material properties of the reinforcement.
Fig. 12 Adhesively plated beam specimens' details

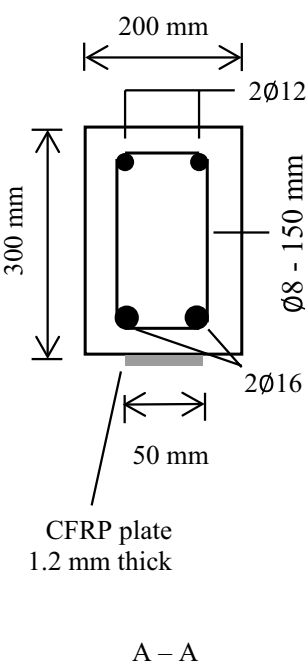

(a)

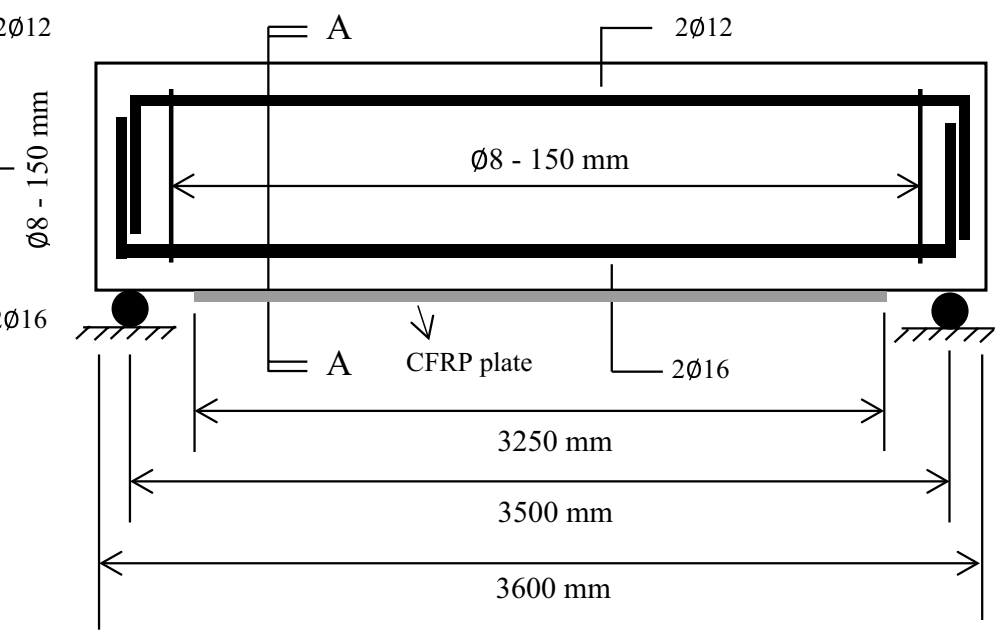

(b) 
Fig. 13 Unplated beam specimens' details

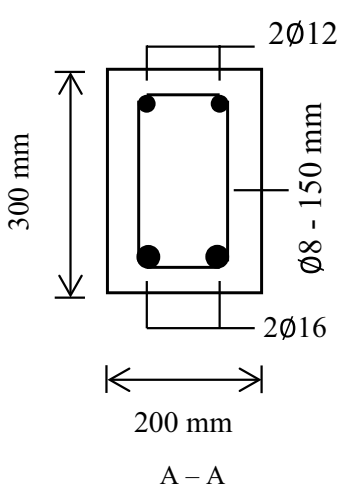

(a)

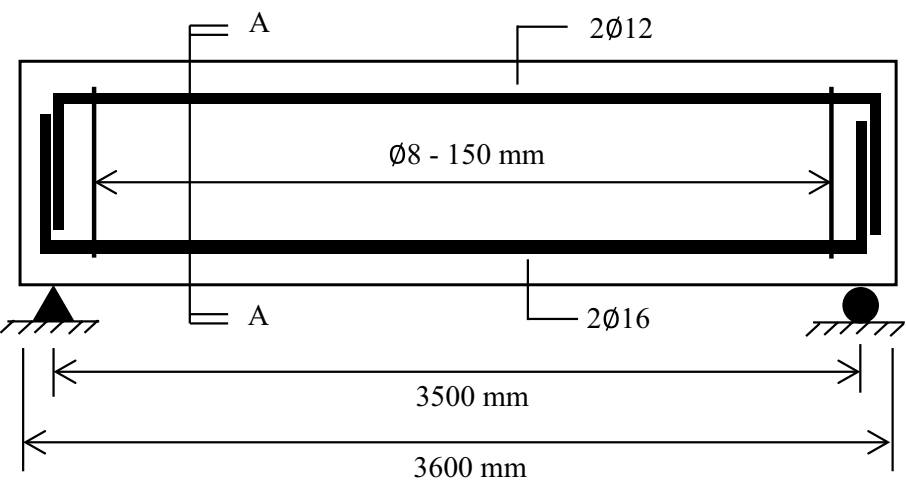

(b)
Table 1 Reinforcement mechanical properties

\begin{tabular}{lll}
\hline Property & $\begin{array}{l}\text { Reinforcement } \\
\text { steel }\end{array}$ & CFRP plate \\
\hline Elastic modulus (GPa) & 154 & 165 \\
Strain-hardening modulus (GPa) & 1.57 & - \\
Yield stress, $\mathrm{f}_{\mathrm{y}}(\mathrm{MPa})$ & 535 & - \\
Fracture tensile strength (MPa) & 615 & 2800 \\
\hline
\end{tabular}

\subsection{Experimental setup}

Using a hydraulic jack, a concentrated load at mid-span was applied on the beams until failure. After each increment, the mid-span strains in the steel rebars and CFRP plate were measured as the test proceeded using strain gauges. The experimental setup is illustrated in Fig. 14. As for the unplated beams, a similar test setup was used in the absence of the plate.

\section{Results and discussion}

In the following subsections, the experimental and theoretical $\mathrm{RC}$ unplated and plated beam results are presented and a comparison between the two is given. This includes the mid-span strain in the steel reinforcement, mid-span strain in the EB plate and ultimate loads.

\subsection{Unplated RC beams}

The mechanics-based solution for the unplated beams was similar to what has been described above except for the fact that no CFRP plate was considered in the analysis. The theoretical and experimental mid-span load-strain results for the steel rebars are presented in Fig. 15 [20]. Clearly, a significant correlation between the two results exists with yielding occurring at a load of about $55 \mathrm{kN}$ (except that for RC-B2). Moreover, Fig. 16 shows the M- relationship for an
$\mathrm{RC}$ beam segment extracted from the unplated RC beam shown in Fig. 13. The RC segment was $290.6 \mathrm{~mm}$ long and the moment-rotation analysis was halted when the reinforcement reached its fracture strain, fract, at $M=57.1 \mathrm{kN} \cdot \mathrm{m}$. Accounting for the self-weight of the beam (concrete unit weight, $c=25 \mathrm{kN} / \mathrm{m}^{3}$ ), the theoretical ultimate load of the unplated RC beams was $62.6 \mathrm{kN}$. Table 2 summarizes the experimental and theoretical ultimate loads for the three $\mathrm{RC}$ beam specimens to which it can be deduced that the mechanics-based solution provides a good estimate of the ultimate load for unplated RC beams as the difference between the theoretical and the average experimental ultimate load was about $0.6 \%$.

\subsection{Adhesively plated RC beams}

The theoretical mid-span applied load versus strain response for the steel reinforcement bars were contrasted with those observed in the laboratory for CFRPB1, CFRP-B2 and CFRP-B3, and the results are presented in Fig. 17a, b, C, respectively. In all of the three beams, it can be deduced that the elastic slope of the mid-span loadstrain response was stiffer for the experimental results as compared to the theoretical ones. Furthermore, from the theoretical load-strain response, the reinforcement steel yielded at a much earlier applied load, $\mathrm{P}$, in contrast to the experimental ones. For instance, the theoretical load-strain response shows that the reinforcement steel yielded at a mid-span load of about $61.55 \mathrm{kN}$ while the experimental results show that yielding occurred at a mid-span load of $68 \mathrm{kN}$ in CFRP-B3 and about $75 \mathrm{kN}$ in CFRP-B2.

As for the mid-span strain in the CFRP plate, the results are given in Fig. 17d. Initially, and prior to cracking of the concrete, the theoretical results were identical to the experimental ones. However, after the formation of flexural cracks, the two results poorly correlate. The slope of the plate's theoretical load-strain response changes three times, first when a single crack intercepts the plate, second when multiple cracks in the concrete segment form and 
Fig. 14 Test setup [22]

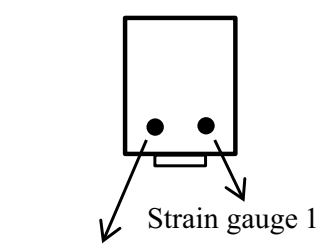

Strain gauge 2

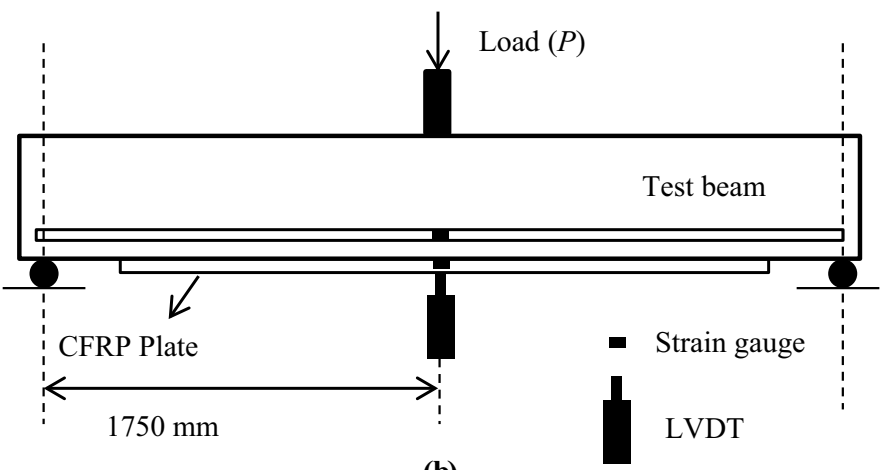

(b)

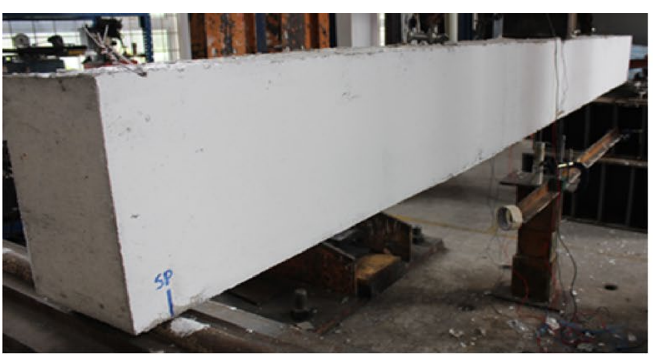

(c)

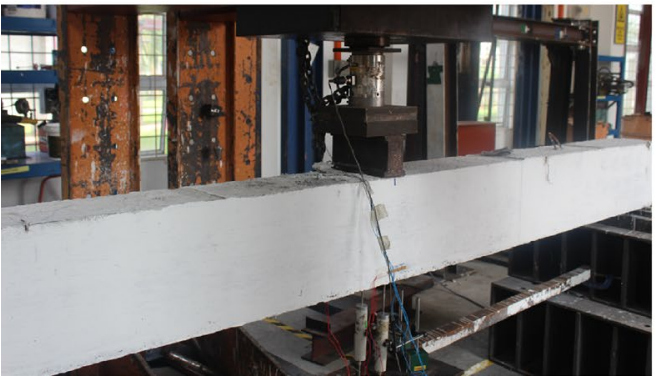

(f)

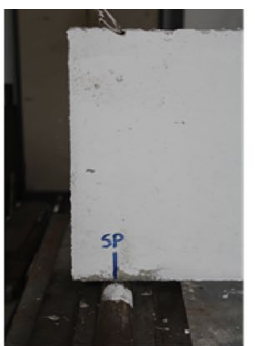

(d)

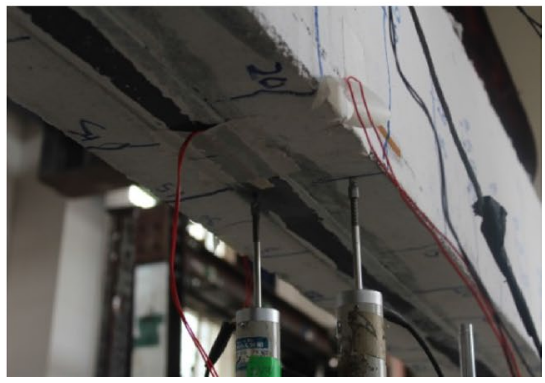

(g) lastly when the force in the plate reaches $\mathrm{P}_{\mathrm{IC}}$ after which the force in the plate remains unchanged with increasing displacement. As opposed to the theoretical results, the observed values in the laboratory for the strain in the plate keep increasing until the plate debonds. The slope of the experimental response changes twice, once when cracking of the concrete takes place and another time when the steel reinforcement yields.

As for the theoretical ultimate moment capacity, the $\mathrm{M}^{-}{ }_{\mathrm{RC}}$ relationship (Fig. 18b) needs to be determined and can be derived from $\mathrm{M}$ - relationship for a passively prestressed segment (Fig. 18a) as explained previously. After that, it becomes a question of determining the moment in the beam that will cause compatibility of displacement at the plate's level. $L_{\text {crit }}$ was determined to be $115 \mathrm{~mm}$ using the expression given by Seracino et al. [31]. Furthermore, the total plate's length was $3250 \mathrm{~mm}$; that is, about $125 \mathrm{~mm}$ unplated distance between the support and the free end of the plate exists. Therefore, compatibility of displacement between the plate and the concrete at the pate's level should be achieved at $240 \mathrm{~mm}$ from the support. This is shown in Fig. 19c, where the load, $\mathrm{P}$, at the center of the beam that caused this displacement was $62.5 \mathrm{kN}$. In other words, the displacement-based approach predicted that debonding failure will occur when the applied load reached $62.5 \mathrm{kN}$. However, from laboratory tests, the plate debonded at an average load of $83.9 \mathrm{kN}$ (Table 3 ) and the results obtained from the displacement-based approach heavily underestimate the maximum load prior to failure. The only way to explain this is due to early yielding of the steel reinforcement in the displacement-based analysis, which caused greater deformation at the level of the plate with little increase in load, and also assuming that the force in the plate does not build up after reaching $\mathrm{P}_{\mathrm{IC}}$.

From a full-interaction analysis [3] of which ${ }_{\mathrm{IC}}$ is taken as 0.00211 , IC debonding occurs at an applied moment of $29.3 \mathrm{kN} \cdot \mathrm{m}$. This in turn results in an ultimate load of 


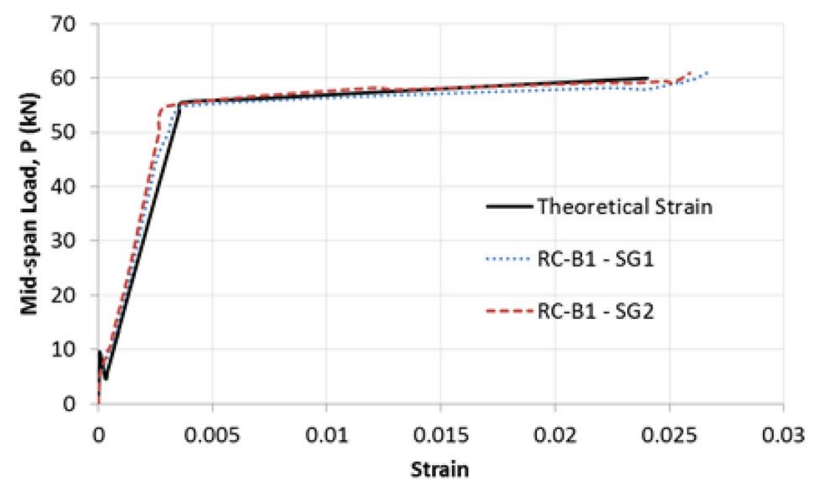

(a)

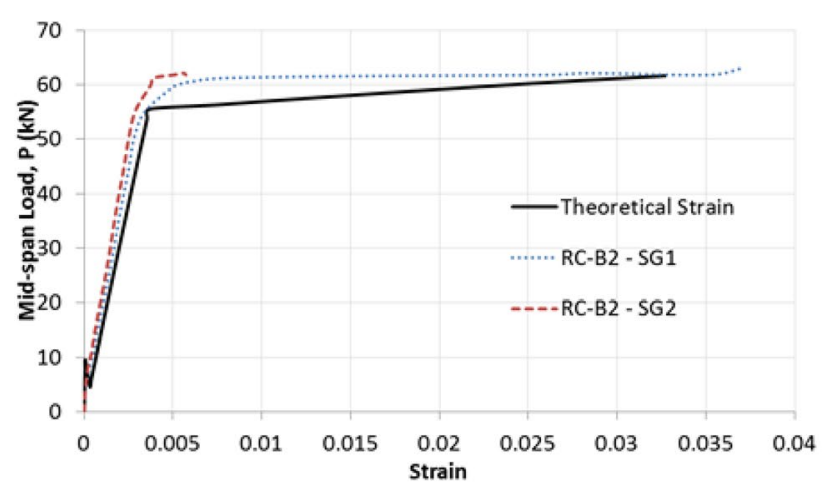

(b)

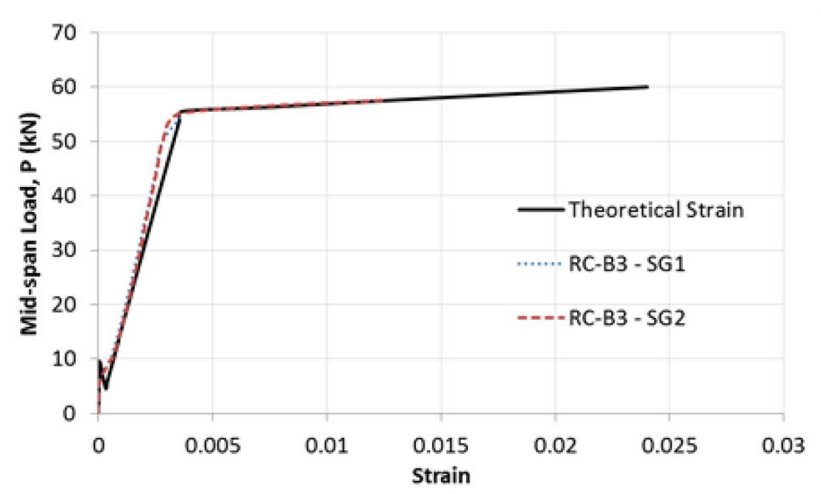

(c)

Fig. 15 Reinforcement steel mid-span strain: (a) RC-B1; (b) RC-B2; (c) RC-B3 [20]

$30.9 \mathrm{kN}$ while accounting for the self-weight of the beam which is clearly much lower than the actual ultimate load derived from the laboratory, and is less than half of that determined from the displacement-based approach (Fig. 20). Furthermore, for all of the plated beams considered here, failure occurred by progressive IC debonding of the plate, and Fig. 19 depicts the beams at the point of failure.

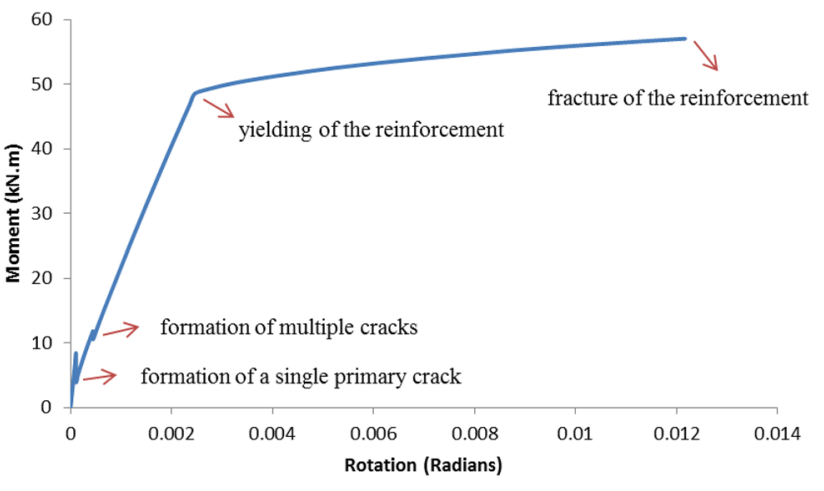

Fig. $16 \mathrm{RC}$ beam M- relationship

\section{Parametric study}

In the following subsections, a parametric study was conducted to see the effect of adding a frictional component to the plate's bondstress-slip characteristic on the global behavior of the CFRP plated RC beams (i.e. reinforcement strain, ultimate load). Furthermore, a separate analysis was also conducted to see the effect of adding and altering the ascending branch of the plate's bondstress-slip model on the behavior of the plated beams.

\subsection{Frictional component in the plate's bondstress-slip model}

The main reason why the reinforcement steel in the CFRP plated beams theoretical $\mathrm{M}$ - analysis yielded at an earlier applied load to that determined in the laboratory was due to the assumption that the plate's force remains at $P_{\mathrm{IC}}$ once achieved. This in turn caused the reinforcement steel to take up any additional force in the tensile region of the beam due to the segment rotation, while in reality some of that force was shared by the plate. This is indicated by the build-up in the plate strain as shown by the experimental results. Henceforth, for the force in the plate to exceed $\mathrm{P}_{\mathrm{IC}}$, the bondstress-slip model (-) needs to allow for shear stresses to develop in the plate when the slip at the crack face exceeds ${ }_{\text {max }}$.

In a quick parametric study, the plate's bondstress-slip model was adjusted to allow for a frictional component as shown in Fig. 21. The value for the residual shear strength was chosen to be $1 / 3$ of $_{\text {max }}$ as in Fig. 21 a and 1/2 of ${ }_{\text {max }}$ as in Fig. 21b, and the objective was to see their effect on the global behavior of the CFRP plated beams. Since the bondstress-slip models do not close at max $^{\prime}$ a closed-form solution for the load-displacement relationship cannot be 
Table 2 RC beams experimental and theoretical ultimate loads

\begin{tabular}{llll}
\hline Beam specimen & $\begin{array}{l}\text { Experimental ultimate } \\
\text { load, } P_{\text {u-exp }}(\mathrm{kN})\end{array}$ & $\begin{array}{l}\text { Theoretical ultimate load, } \\
\mathrm{P}_{\text {u-theo }}(\mathrm{kN})\end{array}$ & $\mathrm{P}_{\mathrm{u} \text {-exp }} / \mathrm{P}_{\mathrm{u} \text {-theo }}$ \\
\hline RC-B1 & 62.44 & 62.6 & 0.997 \\
RC-B2 & 64.26 & 62.6 & 1.027 \\
RC-B3 & 62.14 & 62.6 & 0.993 \\
Average ultimate load, $\mathrm{P}_{\text {avg }}$ & 62.95 & 62.6 & 1.006 \\
\hline
\end{tabular}

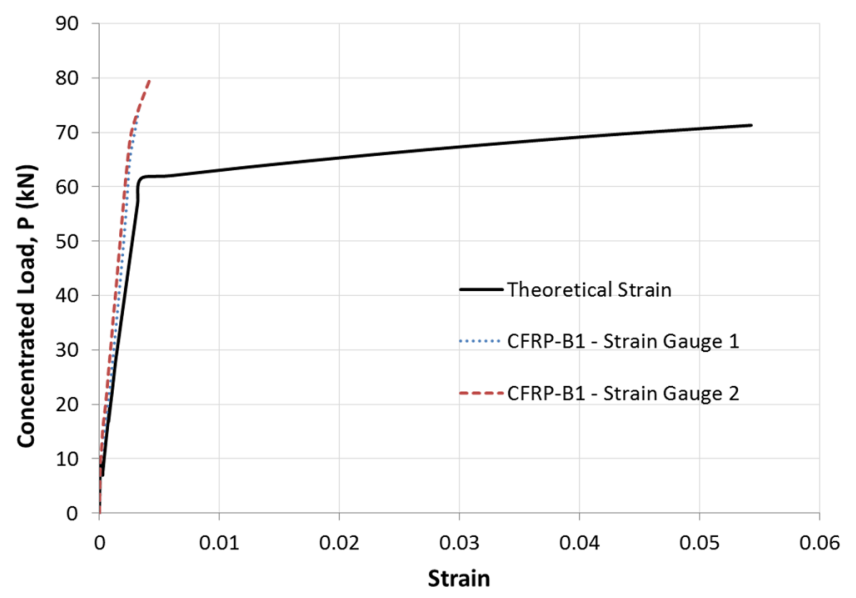

(a)

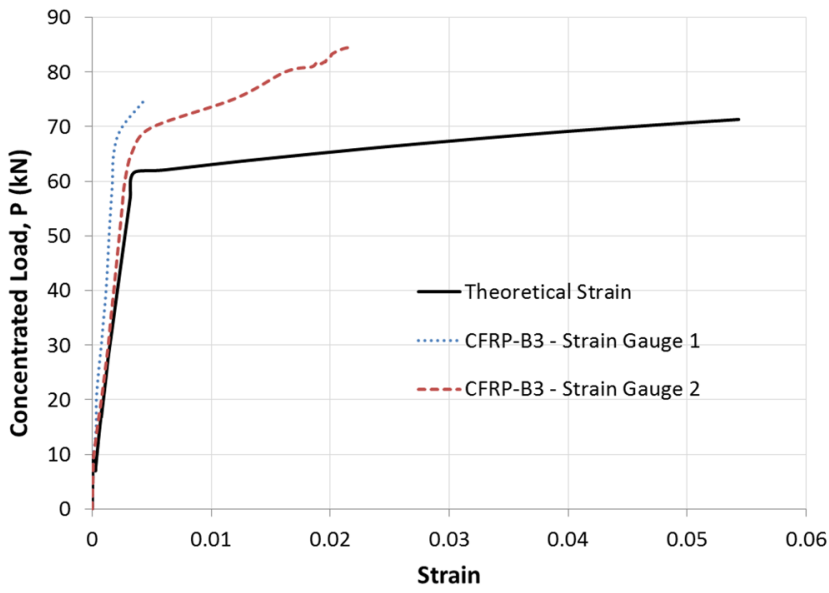

(c)

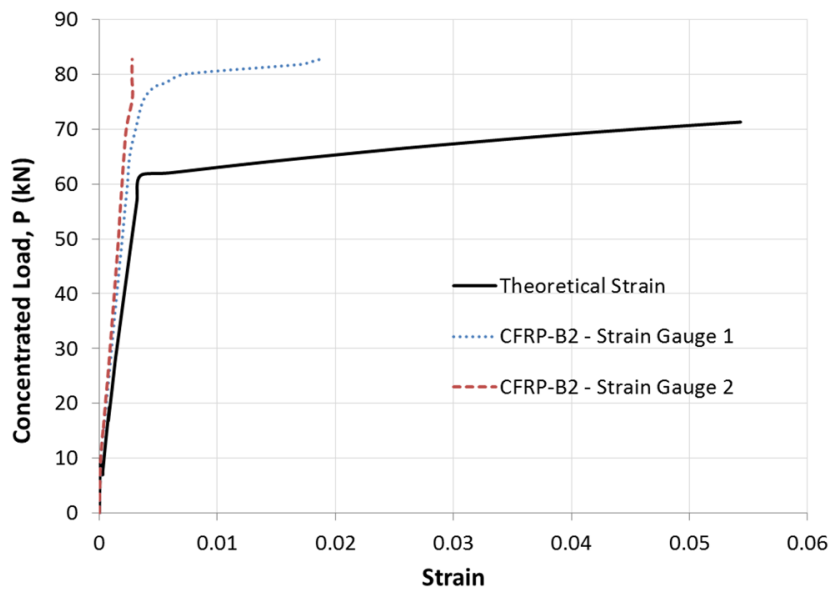

(b)

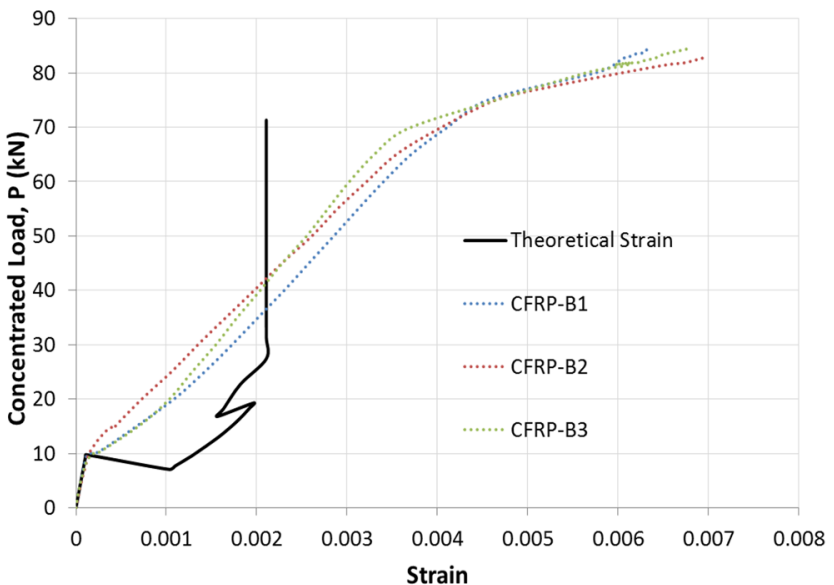

(d)

Fig. 17 Mid-span strain results: (a) CFRP-B1 reinforcement steel; (b) CFRP-B2 reinforcement steel; (c) CFRP-B3 reinforcement steel; (d) CFRP plate

developed; instead, Haskett et al. [13] partial-interaction numerical solution which accommodates any shape of the bondstress-slip model can be utilized to determine the load-slip relationship. Other than that, the analysis is similar to what has been described earlier.

The theoretical strains of the reinforcement steel derived from the moment-rotation analysis were compared with the experimental results of CFRP-B3 and are depicted in Fig. 22a. The line referred to as "Theoretical Strain" was derived from the moment-rotation analysis where the linear-descending bondstress-slip model was used. On the other hand, the lines referred to as "Modified Theoretical Strain 1" and "Modified Theoretical Strain 2 " were derived from a moment-rotation analysis in which 


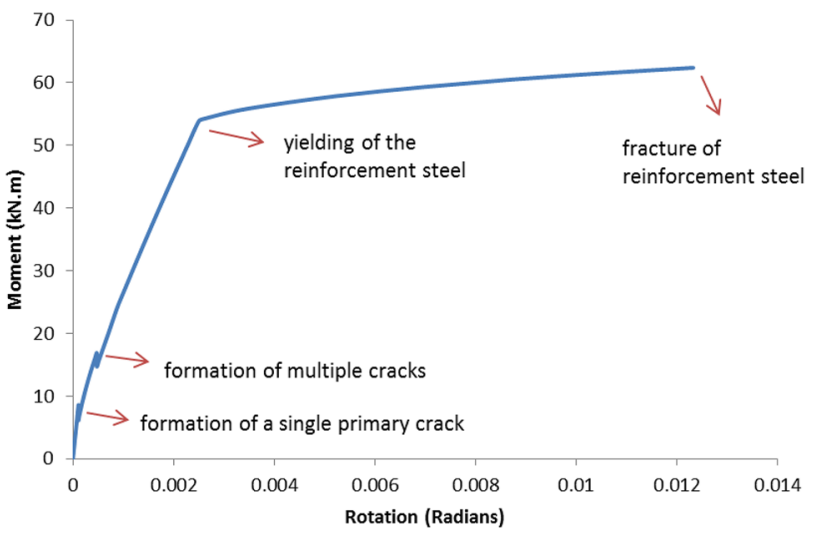

(a)

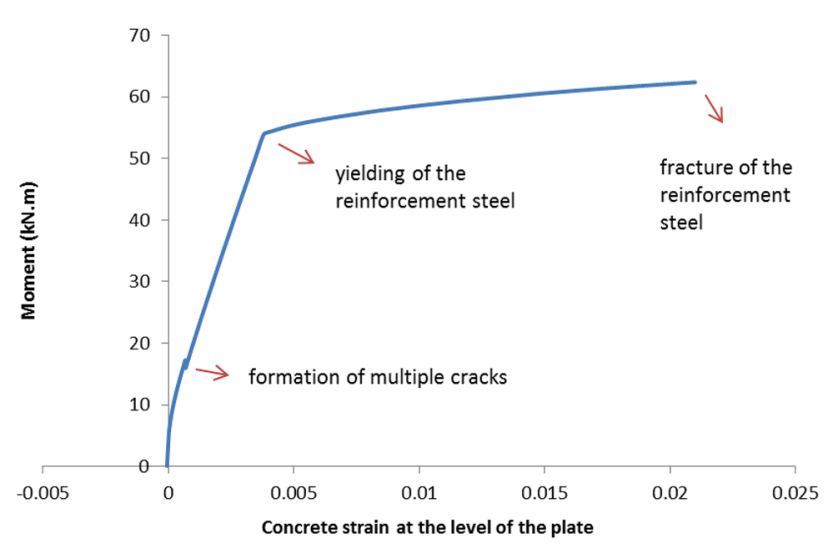

(b)

Fig. 18 Passively prestressed segment: (a) $M-;$ (b) $M_{-}{ }_{R C}$

the bondstress-slip models shown in Fig. 21a, b were used, respectively. Finally, the load-strain response named "CFRP-B3-Strain Gauge 1" and "CFRP-B3-Strain Gauge 2" represent the experimental results determined in the laboratory for CFRP-B3. From the results, it can be deduced that introducing a frictional component in the bondstress-slip relationship in fact permitted the reinforcement steel to yield at a much higher load in the theoretical solution, and the larger the frictional component the higher the load required to cause the steel reinforcement to yield. As for the strains in the CFRP plate depicted in Fig. 22b, it can be seen that the modified theoretical strains 1 and 2 provide a better solution to the strain in the plate when compared to the theoretical strain response. For instance, the modified theoretical strains tend to approach the recorded experimental strains in the plate and give good correlation when the reinforcement steel yields after a load of about $65 \mathrm{kN}$. This is opposed the theoretical strain in Fig. 22b where no frictional component is considered in the analysis and the strain in the plate remains at the IC debonding strain, $\varepsilon_{\mid \mathrm{C}}$ after reaching the maximum slip, $\delta_{\max }$. Figure $22 \mathrm{~b}$ illustrates that at service loads, the results correlate poorly with experimental values, indicating that a linear-descending branch does little to simulate the behavior of the plated member at service loads.

Finally, the displacement-based approach was utilized to predict the ultimate load to cause the concrete displacement to equal the plate's displacement at a distance $L_{\text {crit }}$ from the plate's free end. The concrete displacement can be calculated using Eq. (33) while the displacement of the plate can be determined by;

$\delta_{\mathrm{db}-\mathrm{p}}=\int_{0}^{\mathrm{L}_{\mathrm{db}}} \varepsilon_{\mathrm{p}}$

where the strain in the plate, $\varepsilon_{\mathrm{p}}$, in Eq. (36) can be determined from the segmental analysis. That is, for each moment $M$, the corresponding $\varepsilon_{\mathrm{p}}$ can be determined and substituted in Eq. (36). The modified ultimate load obtained when the bondstress-slip model was similar to that in Fig. 21a was $80 \mathrm{kN}$, and $87.5 \mathrm{kN}$ when the bondstress-slip model was similar to that in Fig. $21 \mathrm{~b}$ (this while accounting for the self-weight of the beams). The displacement-based ultimate load results are illustrated in Figs. 23 and 24 where the displacement in the FRP plate equaled the displacement in the concrete at the same level at distance $L_{\text {crit }}$ from the end of the plate. Clearly, adding a frictional component to the bondstress-slip model allowed the theoretical ultimate load to increase beyond that of the unplated beam and much closer to the average experimental ultimate load $(83.9 \mathrm{kN})$.

\subsection{Ascending branch of the bondstress-slip relationship}

The poor correlation between the plate's theoretical strain and experimental strains at low loads (Fig. 22b) can be attributed to the fact that a linear-descending bondstressslip model was utilized in the analysis. Therefore, to see the effect of adding an ascending branch to the bondstressslip property on the strain response, a parametric study was conducted.

Initially, the properties of the bondstress-slip model adopted in the analysis above was kept the same (i.e. maximum bondstress, $\tau_{\max }$ and maximum slip, $\delta_{\max }$ ) with the addition of an ascending branch as depicted in Fig. 25a. The values for the slip at which the maximum bondstress is achieved, $\delta_{1}$, were taken as $0.03 \mathrm{~mm}, 0.05 \mathrm{~mm}$ and 
(a)

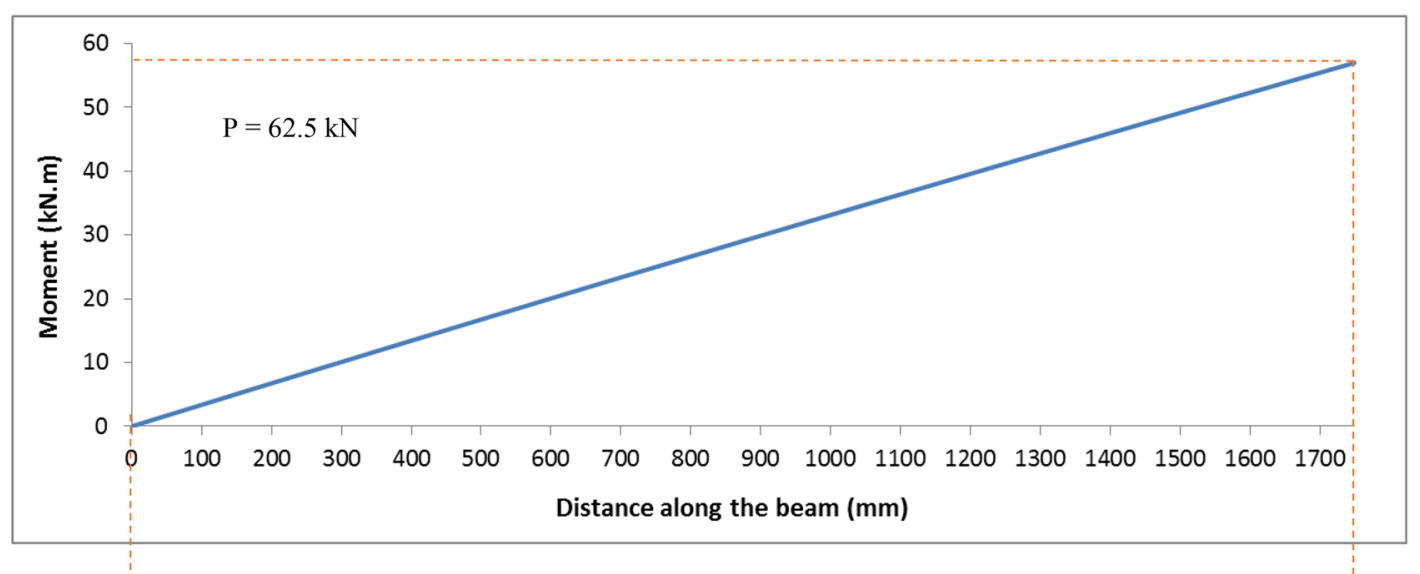

(b)

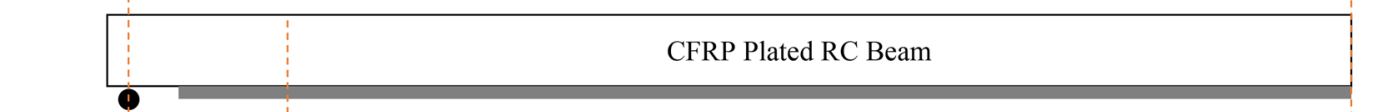

(c)

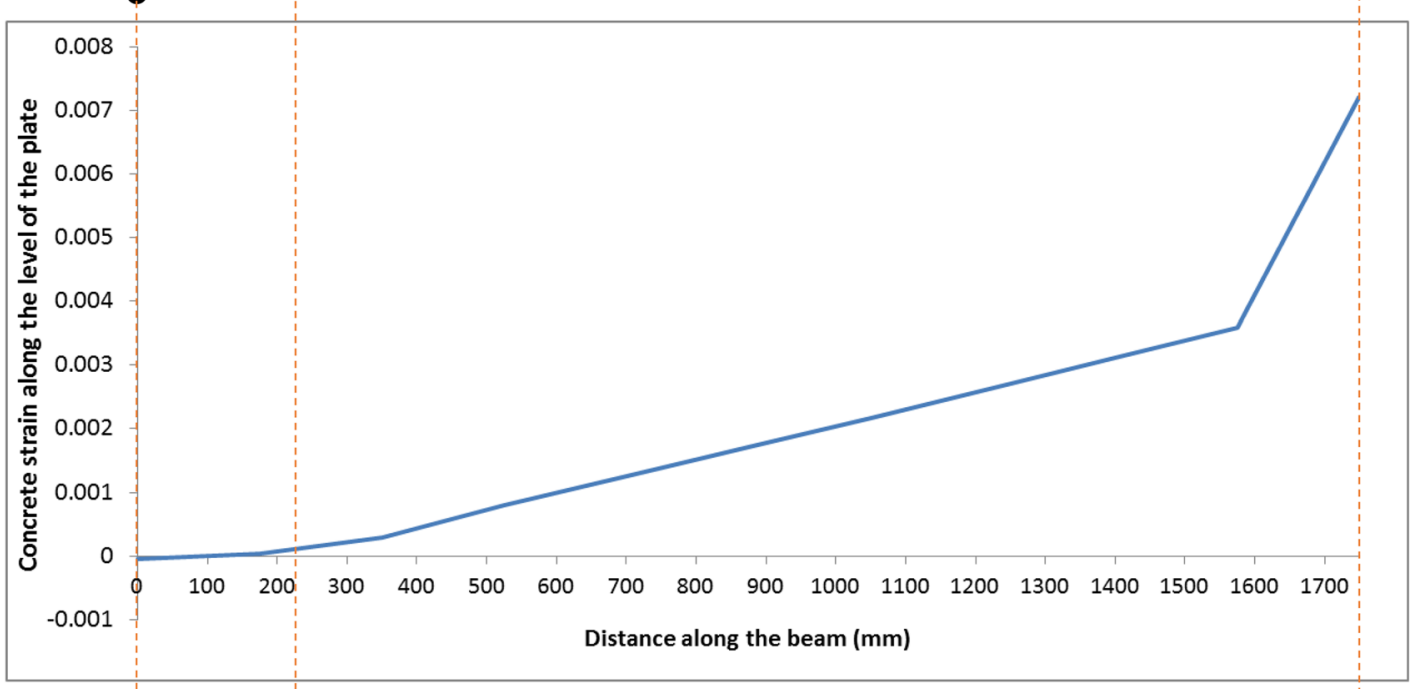

(d)

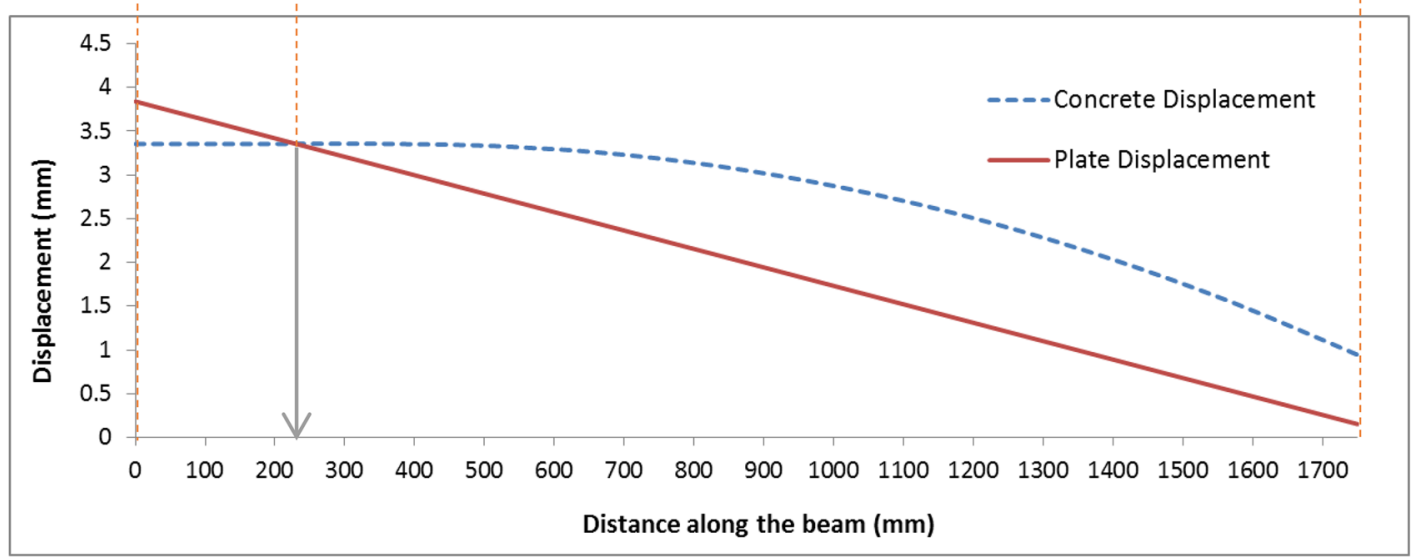

Fig. 19 Displacement-based analysis: (a) Moment; (b) CFRP plated beam; (c) concrete strain along the level of the plate; (d) concrete and plate displacements 
Table 3 CFRP RC beams experimental and theoretical ultimate loads

\begin{tabular}{llll}
\hline Beam specimen & $\begin{array}{l}\text { Experimental ultimate } \\
\text { load, } \mathrm{P}_{\text {u-exp }}(\mathrm{kN})\end{array}$ & $\begin{array}{l}\text { Theoretical ultimate load, } \\
\mathrm{P}_{\text {u-theo }}(\mathrm{kN})\end{array}$ & $\mathrm{P}_{\text {u-exp }} / \mathrm{P}_{\mathrm{u} \text {-theo }}$ \\
\hline CFRP-B1 & 84.3 & 62.5 & 1.35 \\
CFRP-B2 & 82.8 & 62.5 & 1.32 \\
CFRP-B3 & 84.6 & 62.5 & 1.35 \\
Average ultimate load, $\mathrm{P}_{\text {avg }}$ & 83.9 & 62.5 & 1.34 \\
\hline
\end{tabular}

Fig. 20 Failure of FRP plated beams [22]

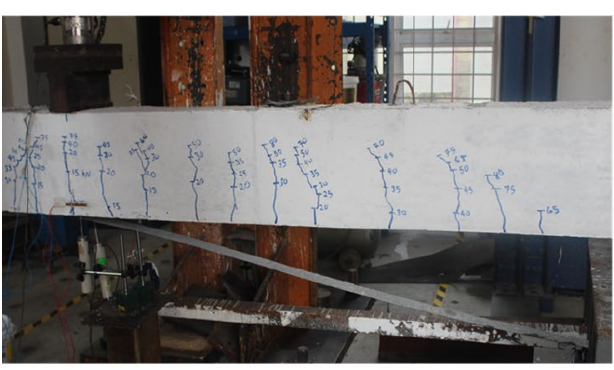

(a) CFRP-B1

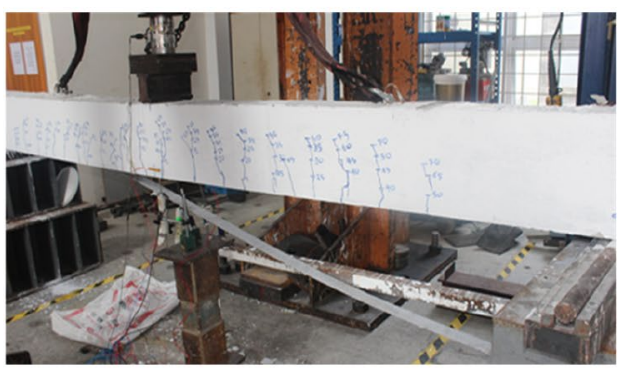

(c) CFRP-B2

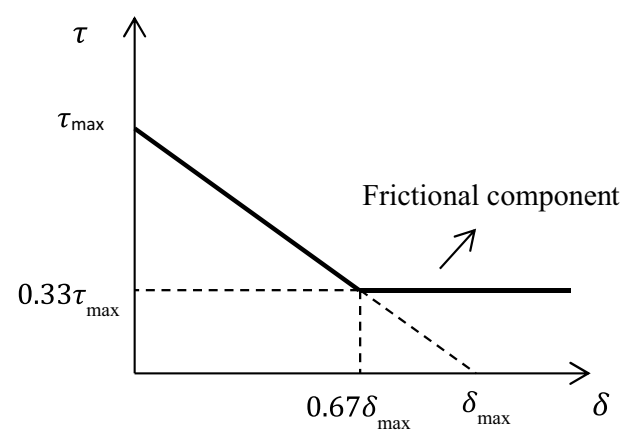

(a)

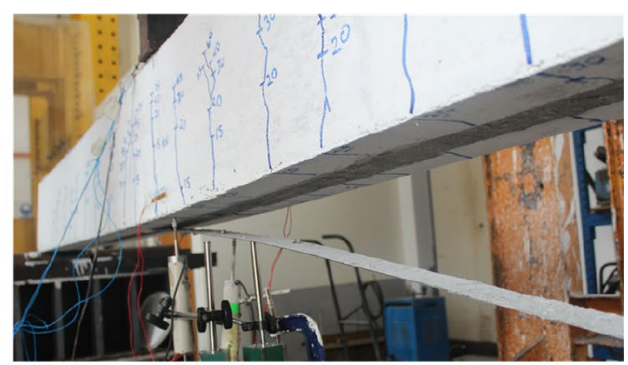

(b) CFRP-B 1

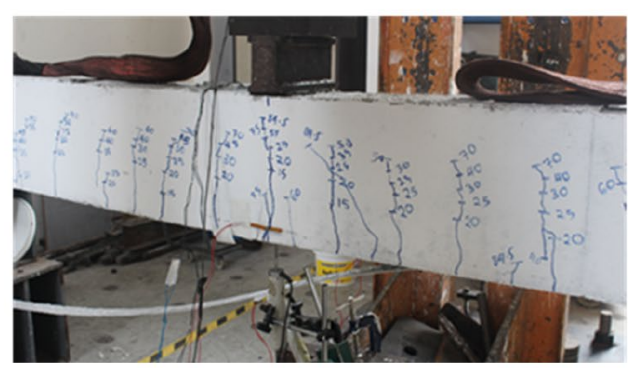

(d) CFRP-B3

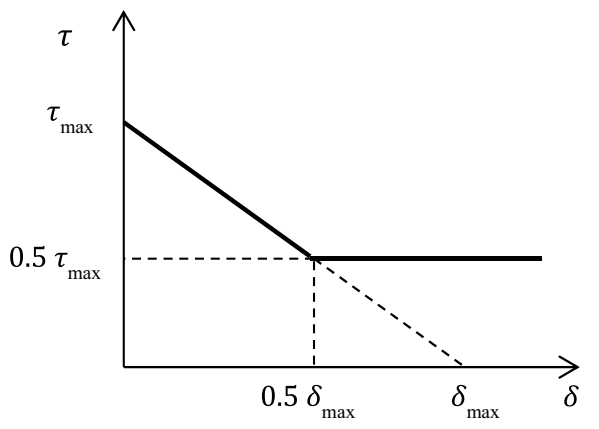

(b)
$0.07 \mathrm{~mm}$ and their effect on the plate strain is illustrated in Fig. 25b. Clearly, the higher the value of $\delta_{1}$, the more the theoretical results move towards the experimental results. That is, a higher $\delta_{1}$ in Fig. 25 meant lower strain development in the plate at service loads. This can be explained by the fact that as cracks from in the CFRP plated beam, the ascending branch with greater $\delta_{1}$ develops less bondstress for the same slip; hence, lower force in the plate and lower strain for the same slip (i.e. same applied load). Moreover, adding an ascending branch gives better results at service 
Fig. 22 Modified strain results: (a) CFRP-B3 reinforcement steel; (b) CFRP plate

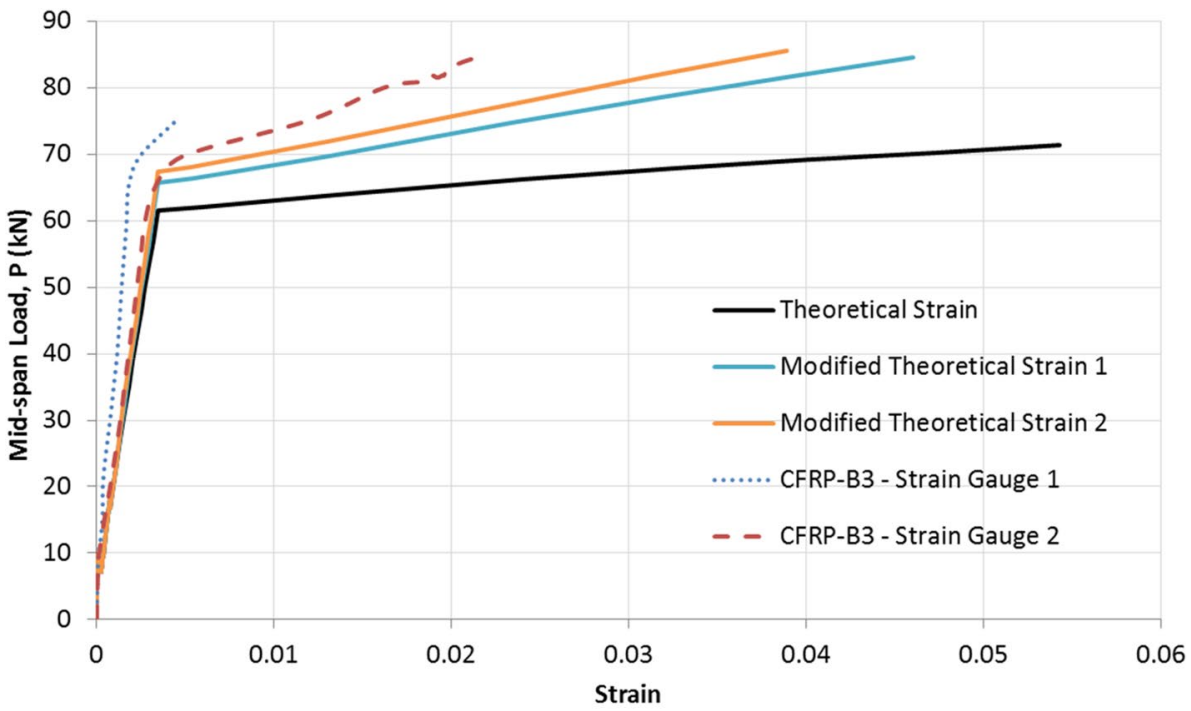

(a)

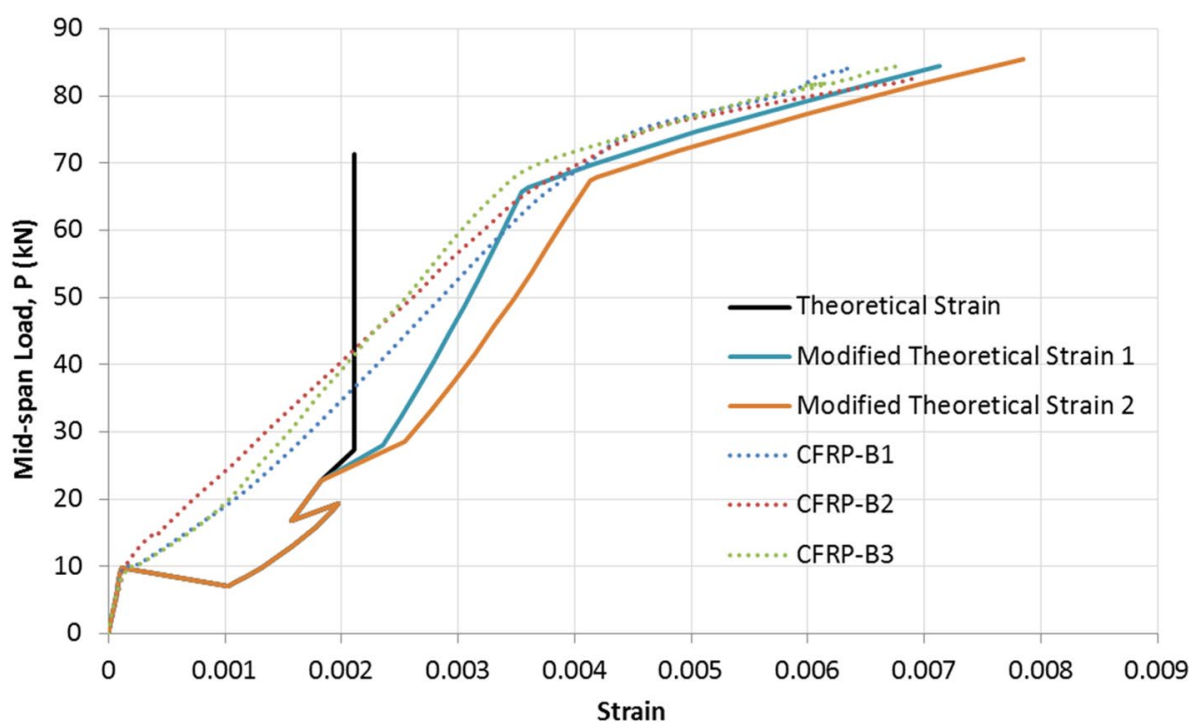

(b) loads than the results derived from the linear-descending branch as can be seen from Fig. 25b. Nevertheless, the change in the plate strain due to different values of $\delta_{1}$ was not significant as can be seen clearly from the Fig. 25b.

Next, to see the effect of altering the maximum slip on the plate's strain, a parametric study was conducted where the maximum slip, $\delta_{\max }$ was changed once to $0.1 \mathrm{~mm}$ and then to $0.2 \mathrm{~mm}$ and $0.25 \mathrm{~mm}$ as shown in Fig. 26a. From the results in Fig. 26b, it can be seen that altering the maximum slip, $\delta_{\text {max }}$ does not have much effect on the strain during early stages of loading and the results were almost identical in all cases. This can be due to the fact that the service behavior of the plated member is heavily influenced by the bondstress at low slip, which was almost the same in all cases as shown in Fig. 26. However, at slightly higher loads, the strain response due to the different bondstress-slip models began to divert, indicating that $\delta_{\max }$ affects the behavior at higher loads. Furthermore, Fig. 27 shows the effect of changing the maximum bondstress, $\tau_{\max }$ on the strain in the plate. Clearly, the lower the $\tau_{\max }$, the closer the theoretical results are to the experimental ones as lower strains form in the plate with 


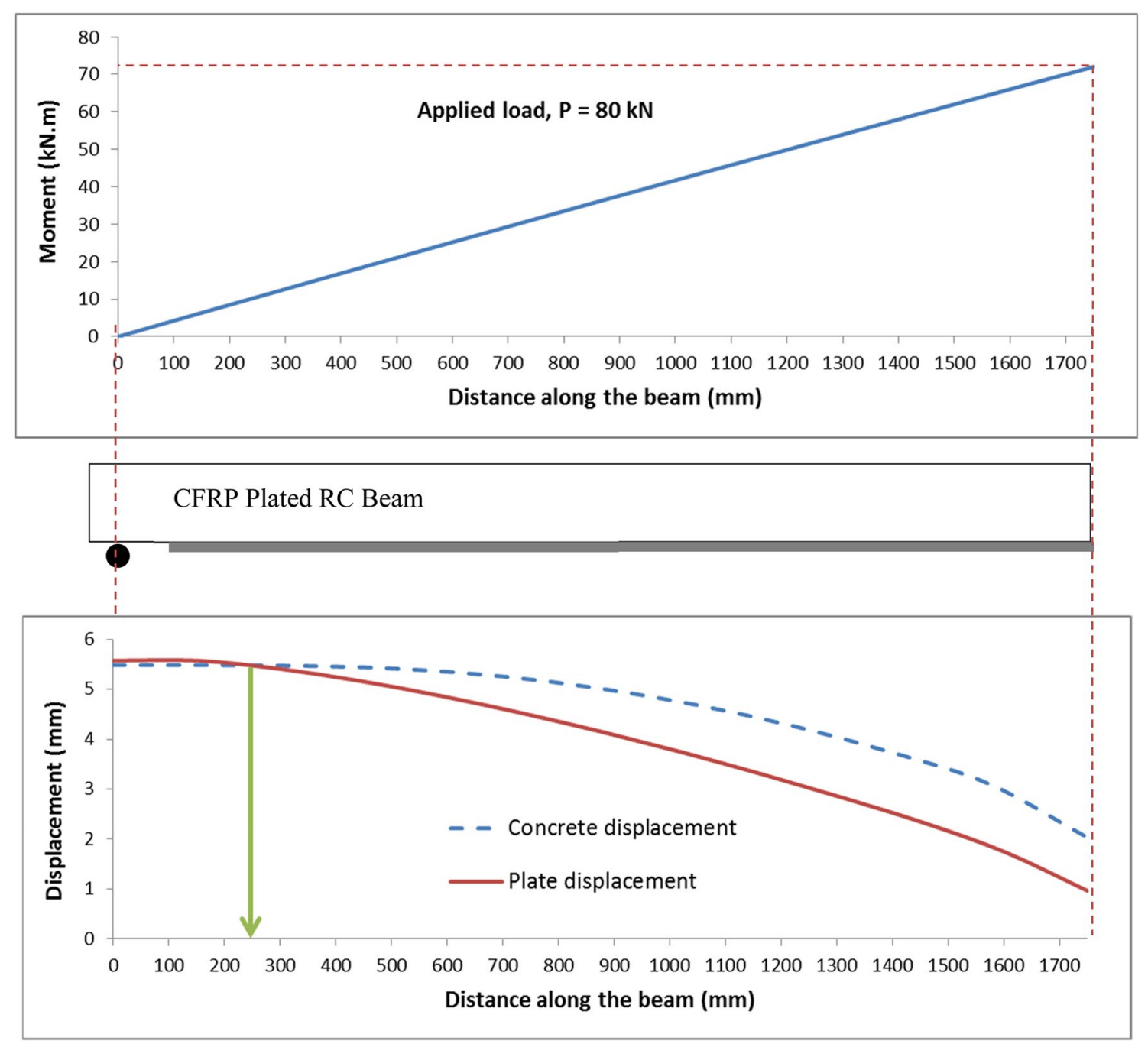

Fig. 23 Ultimate load of CFRP plated RC Beam with $0.33_{\max }$ frictional component

increase in slip (Fig. 27b). Also, altering $\tau_{\max }$ in the bondstress-slip model significantly influences the behavior at service loads, where the strain response in Fig. $27 \mathrm{~b}$ varies greatly from one bondstress-slip model to the other.

From the above parametric study, a more accurate bondstress-slip characteristic for the plate that would give better results of the strain at service loads for the beams considered here would have an ascending branch with a considerable $\delta_{1}$, and $\tau_{\max }$ smaller than the $5.23 \mathrm{~N} / \mathrm{mm}^{2}$ used in the preceding analysis. Table 4 gives the values of $\tau_{\text {max }} \delta_{1}$ and $\delta_{\max }$ based on different bi-linear bondstressslip models available in the literature, and summarized in Table 5, for the CFRP plated beams considered in this study. The formulas in Table 5 give for each bondstress-slip model the equation for the ascending branch, descending branch, maximum bondstress, $\tau_{\max }$ slip at maximum bondstress, $\delta_{1}$, maximum slip, $\delta_{\text {max }}$ and the expression for any related variables used. As such, the values in Table 4 were the outcome of direct substitution in the equations given in Table 5. Looking at such results, and bearing in mind the findings of the parametric study, the model presented by Ko et al. [35] gives the greatest $\delta_{1}$ and lowest $\tau_{\max }$ among all the models considered in Table 4. Moreover, both Monti et al. [36] and Brosens and Van Gemert [37] models give the greatest value of $\delta_{\max }$ at approximately $0.44 \mathrm{~mm}$, and Nakaba et al. [38] bondstress-slip model gives the greatest bondstress, $\tau_{\max }$, of about $6.33 \mathrm{~N} / \mathrm{mm}^{2}$. The strain in the CFRP plate against the applied mid-span load, while adopting Ko et al. [35] bondstress-slip model for the plate, is given in Fig. 28. 


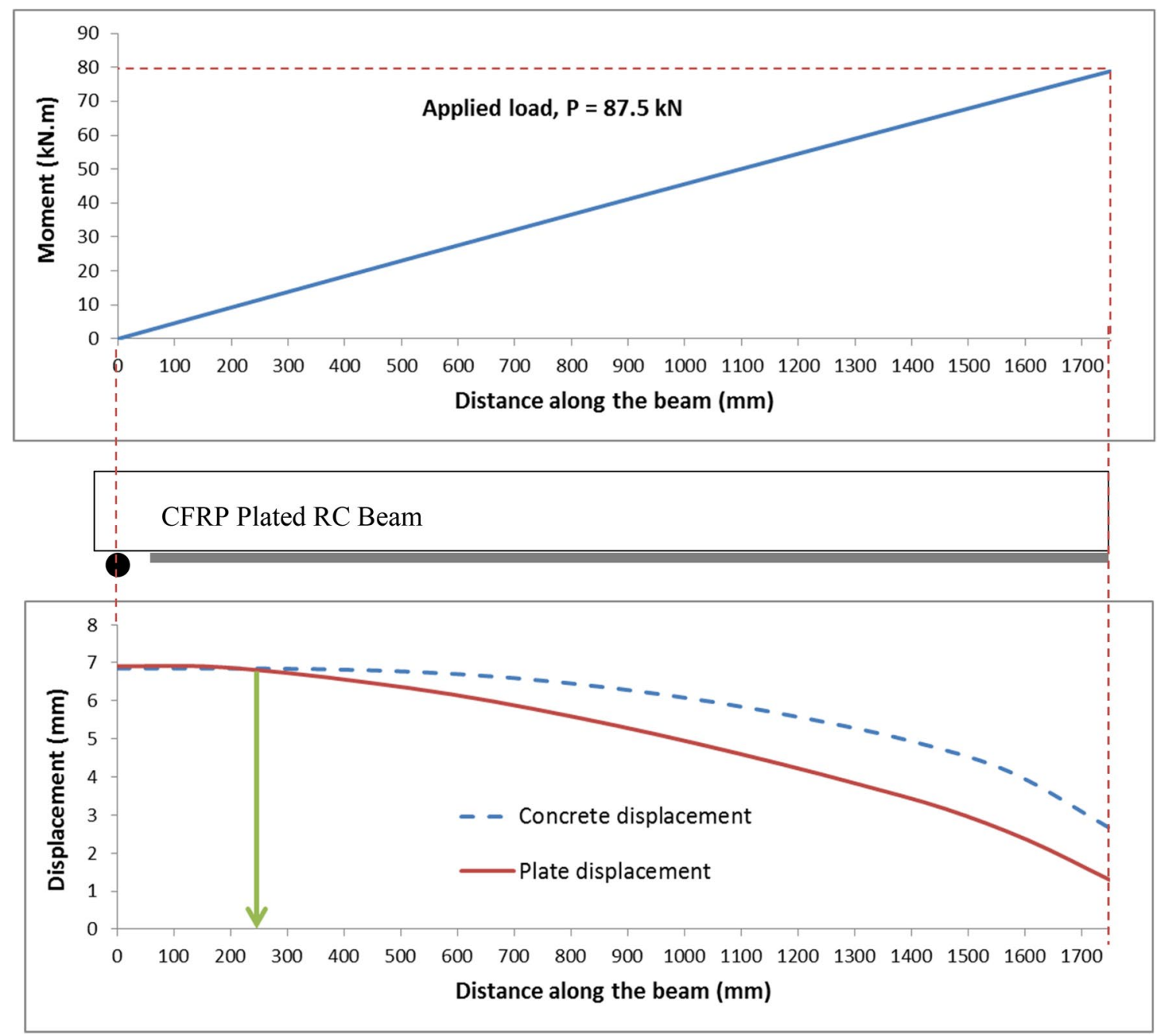

Fig. 24 Ultimate load of CFRP plated RC Beam with $0.5_{\max }$ frictional component

\section{Conclusion}

Using a displacement-based approach that incorporates member debonding mechanism in the design of CFRP plated beams allows for greater ductility to be achieved in the plate as opposed to a full-interaction approach. In this paper, the analytical results of a displacement-based approach introduced by Oehlers et al. [11] were compared against the experimental values for three CFRP plated RC beam specimens. From the analysis, and due to using a bondstress-slip model for the plate without a residual shear component, the steel reinforcement yielded at an earlier applied load to that observed in the laboratory. Throughout this paper, it was shown how changing the adopted bondstress-slip model of the plate affects the analytical results and gives better correlation with the experimental findings. The findings of this study can be best summarized as follows:

- Using a linear-descending bondstress-slip model for the FRP plates resulted in poor correlation with the experimental findings at the ultimate limit state. For 


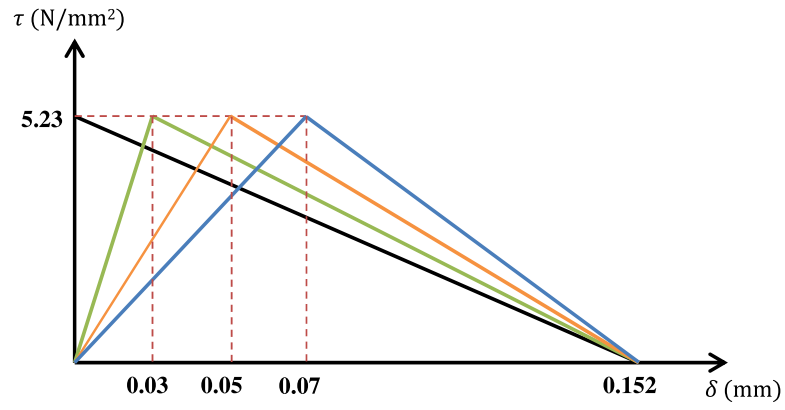

(a)

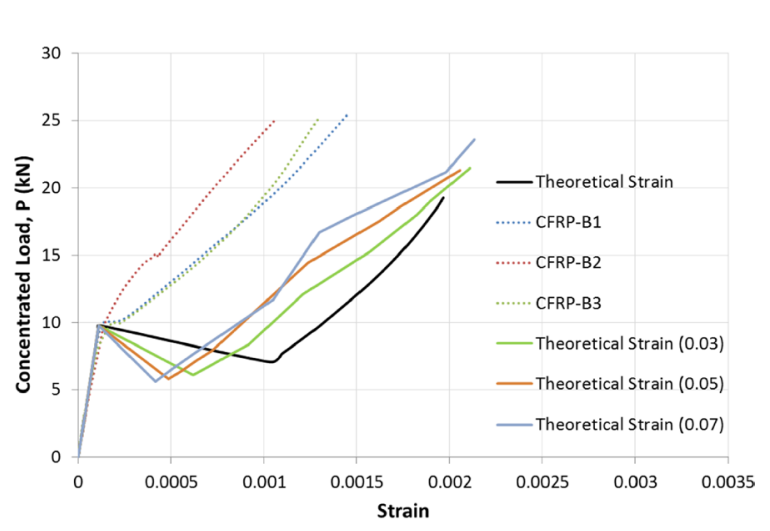

(b)

Fig. 25 Altering the slip at maximum bondstress, 1

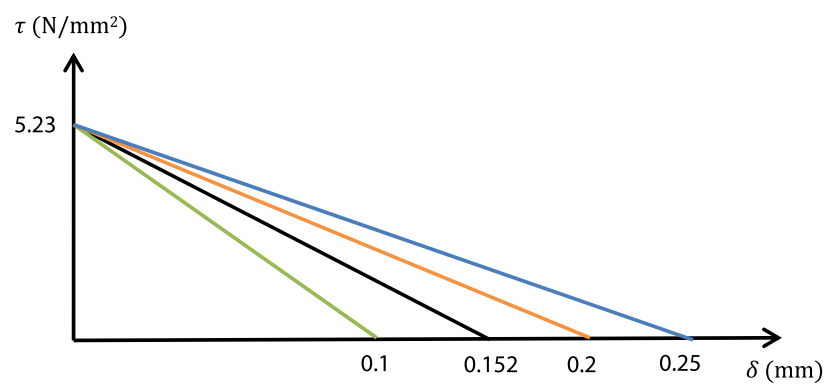

(a)

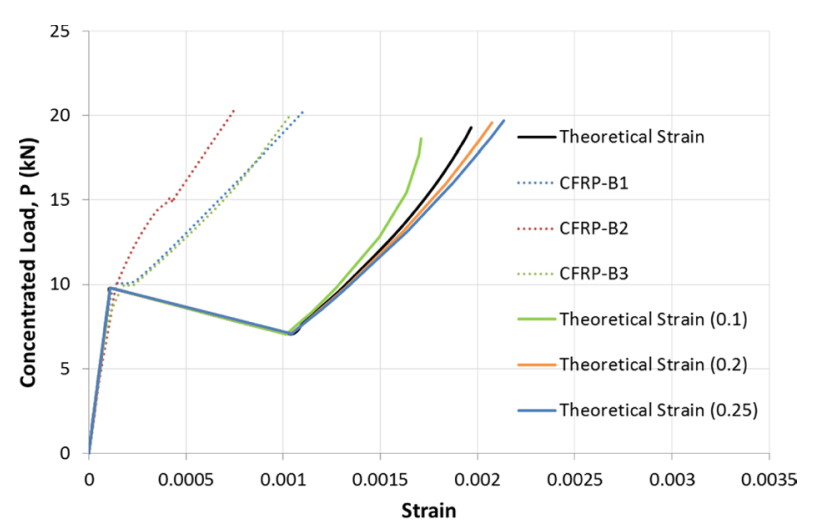

(b)

Fig. 26 Altering the maximum slip, max

\section{SN Applied Sciences}

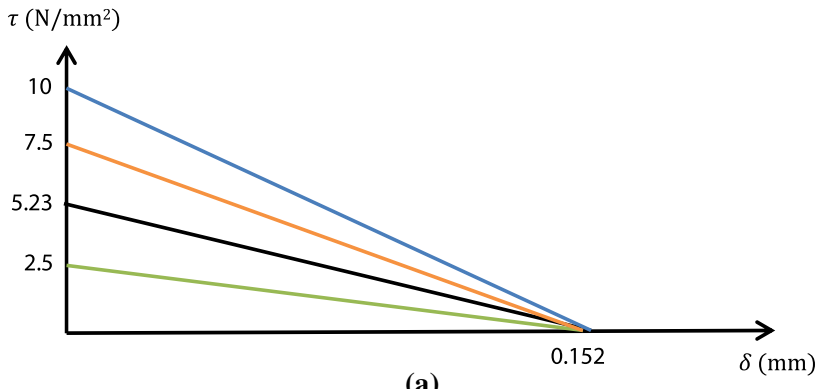

(a)

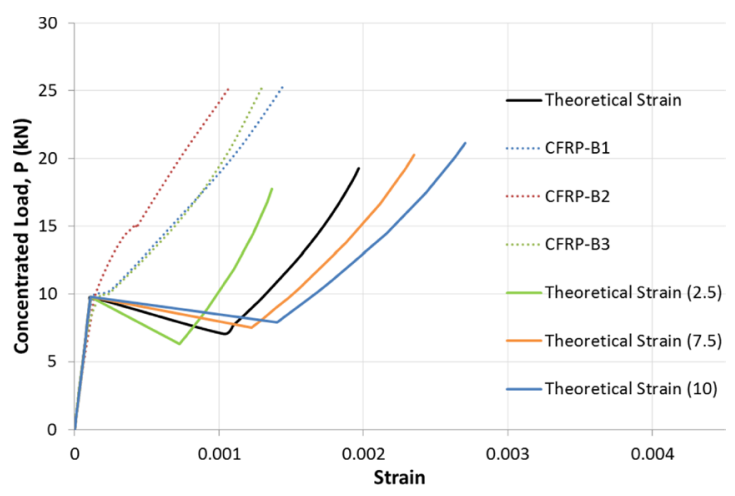

(b)

Fig. 27 Altering the maximum bondstress, max

Table 4 CFRP plate Bondstress-slip parameters from various models

\begin{tabular}{llll}
\hline Ref. & $\delta_{1}(\mathrm{~mm})$ & $\delta_{\max }(\mathrm{mm})$ & $\begin{array}{l}\tau_{\max }(\mathrm{N} / \\
\left.\mathrm{mm}^{2}\right)\end{array}$ \\
\hline Ko et al. [35] & 0.0993 & 0.257 & 3.75 \\
Seracino et al. [31] & - & 0.152 & 5.23 \\
Monti et al. [36] & 0.0353 & 0.437 & 5.93 \\
Nakaba et al. [38] & 0.065 & - & 6.33 \\
Brosens and Van Gemert [37] & 0.0353 & 0.441 & 5.93 \\
\hline
\end{tabular}

instance, the experimental ultimate load results were on average $34 \%$ greater than the theoretical predictions when no frictional component was incorporated in the analysis.

- The higher the adopted residual shear strength component in the FRP plate's bondstress-slip model, the higher the flexural strength achieved from a displacement-based approach.

- Yielding of the steel reinforcement in the theoretical solution is delayed when incorporating a frictional component in the bondstress-slip model for the plate.

- Adopting a linear-descending bondstress-slip model for the plate gives poor results at service loads, and better predictions can be achieved using bi-linear models. 
Table 5 Existing bond-slip models

\begin{tabular}{|c|c|c|c|}
\hline Bondstress-slip model & Ko et al. [35] & Seracino et al. [31] & Monti et al. [36] \\
\hline Ascending branch & $\tau_{\max }\left(\frac{\delta}{\delta_{1}}\right)$ & - & $\tau_{\max }\left(\frac{\delta}{\delta_{1}}\right)$ \\
\hline Descending branch & $\frac{\tau_{\max }\left(\delta_{\max }-\delta\right)}{\left(\delta_{\max }-\delta_{1}\right)}$ & $\frac{\tau_{\max }\left(\delta_{\max }-\delta\right)}{\left(\delta_{\max }\right)}$ & $\frac{\tau_{\max }\left(\delta_{\max }-\delta\right)}{\left(\delta_{\max }-\delta_{1}\right)}$ \\
\hline Maximum bondstress, $\max$ & $0.165 f_{c}$ & $\left(0.802+0.078 \varphi_{f}\right) f_{c}^{0.6}$ & $1.8 \beta_{w} f_{t}$ \\
\hline Slip at maximum bondstress, 1 & $-0.001 f_{c}+0.122$ & - & $2.5 \tau_{\max }\left(\frac{t_{a}}{E_{a}}+\frac{50}{E_{c}}\right)$ \\
\hline Maximum slip, $\max$ & $-0.002 f_{c}+0.302$ & $\frac{0.976 \varphi_{f}^{0.526}}{0.802+0.078 \varphi_{f}}$ & $0.33 \beta_{w}$ \\
\hline Variables & - & $\begin{array}{l}\varphi_{f}=\frac{d_{f}}{b_{f}}=\frac{t_{d}}{2 t_{b}+b_{p}} \\
t_{d}=t_{b}=1\end{array}$ & $\beta_{w}=\sqrt{\frac{1.5\left(2-\frac{b_{p}}{b_{c}}\right)}{1+b_{p} / 100}}$ \\
\hline Type & Bilinear model & Linear-descending model & Bilinear model \\
\hline Bondstress-slip model & Nakaba et al. [38] & Brosens and Van Gemert [37] & \\
\hline Ascending branch & $\tau_{\max }\left(\frac{\delta}{\delta_{1}}\right)[3 /(2+$ & $\tau_{\max }\left(\frac{\delta}{\delta_{1}}\right)$ & \\
\hline Descending branch & - & $\frac{\tau_{\max }\left(\delta_{\max }-\delta\right)}{\left(\delta_{\max }-\delta_{1}\right)}$ & \\
\hline Maximum bondstress, $\max$ & $3.5 f_{c}^{0.19}$ & $1.8 \beta_{w} f_{t}$ & \\
\hline Slip at maximum bondstress, 1 & 0.065 & $2.5 \tau_{\max }\left(\frac{t_{a}}{E_{a}}+\frac{50}{E_{c}}\right)$ & \\
\hline Maximum slip, max & - & & \\
\hline Variables & - & $\beta_{w}=\sqrt{\frac{1.5\left(2-\frac{b_{p}}{b_{c}}\right)}{1+b_{p} / 100}}, G_{f}=0.3 \beta_{w}{ }^{2} f_{t}$ & \\
\hline Type & Non-linear model & Bilinear model & \\
\hline
\end{tabular}

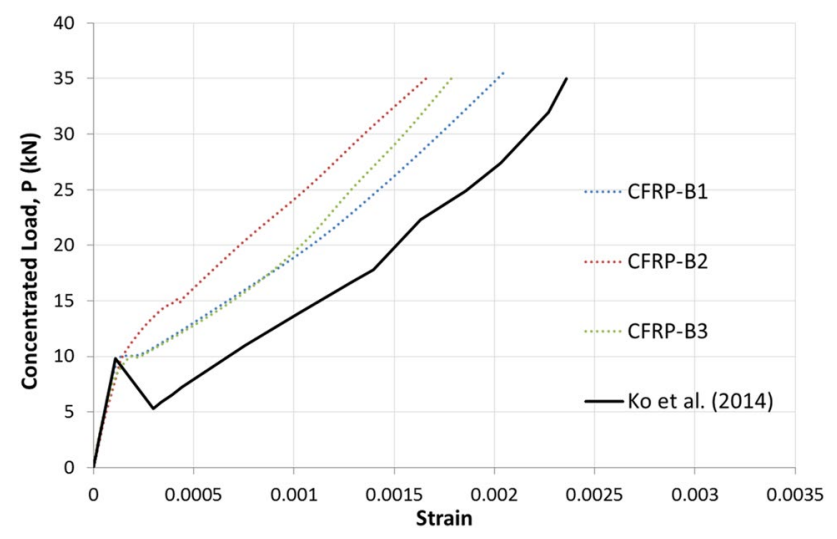

Fig. 28 CFRP plate strain based on Ko et al. [35] bondstress-slip model

- Altering the maximum slip, $\delta_{\max }$ in the bondstress-slip model for the FRP plate has a reduced effect on the serviceability response of the plated member.
- Changing the maximum bondstress, $\tau_{\max }$ in the bondstress-slip model resulted in a considerable change in the serviceability response of the plated member. For instance, a lower $\tau_{\max }$ was seen to result in lower service strains while a higher $\tau_{\max }$ would mean the opposite.

- For the same $\tau_{\max }$ and $\delta_{\max }$, having a greater value of $\delta_{1}$ in the bondstress-slip model for the FRP plate resulted in lower strains in the plate at low service loads.

Subsequent research on the topic should focus on introducing a bondstress-slip model for EB FRP plates that allows for the force in the plate to keep building up after reaching $\mathrm{P}_{\mathrm{IC}}$. This might mean that the bondstressslip model might have residual shear strength due to friction over the debonded region. Moreover, future research can focus on quantifying the factors that affect the frictional component in bondstress-slip models. Finally, to accurately determine the strains in the plate at service loads, the ascending branch of the bondstressslip model must be simulated accurately. 
Acknowledgements The authors acknowledge the support of Universiti Putra Malaysia while conducting this study.

Funding This work was financially supported by Putra Grant, Universiti Putra Malaysia (Grant No. 9555600).

Availability of data and materials Not applicable.

Code availability Not applicable.

\section{Compliance with ethical standards}

Conflict of interest The authors declare that they have no conflict of interest.

\section{References}

1. Amran YHM, Alyousef R, Rashid RSM, Alabduljabbar H, Hung CC (2018) Properties and applications of FRP in strengthening RC structures: A review. Structures 16:208-238

2. Abid SR, Al-lami K (2018) Critical review of strength and durability of concrete beams externally bonded with FRP. Cogent Eng 5(1):1525015 https://doi.org/10.1080/23311 916.2018.1525015

3. Oehlers DJ, Seracino R (2004) Design of FRP and steel plated RC structures: retrofitting beams and slabs for strength, stiffness and ductility. Elsevier, Oxford, UK

4. $\mathrm{ACl}$ (American Concrete Institute) (2008) Guide for the design and construction of externally bonded FRP systems for strengthening concrete structures. $\mathrm{ACl} 440.2 \mathrm{R}$, Detroit

5. Rahimi H, Hutchinson A (2001) Concrete beams strengthened with externally bonded FRP plates. J Compos Constr 5(1):4456 https://doi.org/10.1061/(ASCE)1090-0268(2001)5

6. Sebastian WM (2001) Significance of midspan debonding failure in FRP-plated concrete beams. J Struct Eng 127(7):792-798 https://doi.org/10.1061/(ASCE)0733-9445(2001)127

7. Li X, Wu G (2018) Finite-element analysis and strength model for IC debonding in FRP-strengthened RC beams. J Compos Constr 22(5):04018030 https://doi.org/10.1061/(ASCE) CC.1943-5614.0000863

8. Jumaat MZ, Rahman MA, Alam MA, Rahman MM (2011) Premature failures in plate bonded strengthened $R C$ beams with an emphasis on premature shear: a review. Int J Phys Sci 6(2):156-168

9. Yao J, Teng JG (2007) Plate end debonding in FRP-plated RC beams-I: experiments. Eng Struct 29(10):2457-2471

10. Liu IST, Oehlers DJ, Seracino R (2007) Study of intermediate crack debonding in adhesively plated beams. J Compos Constr 11(2):175-183 https://doi.org/10.1061/ (ASCE) 1090-0268(2007)11

11. Oehlers DJ, Visintin P, Lucas W (2015) Flexural strength and ductility of FRP-plated RC beams: fundamental mechanics incorporating local and global IC debonding. J Compos Constr 20(2):04015046

12. Haskett M, Oehlers DJ, Mohamed Ali MS, Sharma SK (2011) Evaluating the shear-friction resistance across sliding planes in concrete. Eng Struct 33:1357-1364

13. Haskett M, Oehlers DJ, Mohamed Ali MS (2008) Local and global bond characteristics of steel reinforcing bars. Eng Struct 30(2):376-383
14. Muhamad R, Ali MSM, Oehlers DJ, Griffith M (2012) The tension stiffening mechanism in reinforced concrete prisms. Adv Struct Eng 15(12):2053-2070

15. Chen Y, Visintin P, Oehlers DJ, Alengaram JU (2014) Size dependent stress-strain model for unconfined concrete. J Struct Eng 140:04013088 https://doi.org/10.1061/(ASCE) ST.1943-541X.0000869

16. Chen Y, Visintin P, Oehlers DJ (2015) Concrete shear-friction material properties: derivation from actively confined cylinder tests. Adv Struct Eng 18(8):1173-1185

17. Haskett M, Oehlers DJ, Mohamed Ali MS, Wu C (2009) Rigid body moment-rotation mechanism for reinforced concrete beam hinges. Eng Struct 31(5):1032-1041

18. Visintin P, Oehlers DJ, Wu C, Haskett M (2012) A mechanics solution for hinges in RC beams with multiple cracks. Eng Struct 36:61-69

19. Muhamad R, Oehlers DJ, Mohamed Ali MS (2013) Discrete rotation deflection of reinforced concrete beams at serviceability. Struct Build 166(3):111-124

20. El-Zeadani M, Raizal Saifulnaz MR, Mugahed Amran YH, Hejazi F, Jaafar MS (2019) Short-term deflection of RC beams using a discrete rotation approach. Int J Adv Struct Eng 11(4):473-490

21. Tayfur Y, Darby A, Ibell T, Orr J, Evernden M (2019) Serviceability of non-prismatic concrete beams: Combined-interaction method. Eng Struct 191:766-774

22. El-Zeadani M, Raizal Saifulnaz MR, Hejazi F, Mugahed Amran YH, Jaafar MS, Alyousef R, Alrshoudi F (2019) Mechanics-based approach for predicting the short-term deflection of CFRP plated RC beams. Compos Struct 225:111169

23. Gravina RJ, Aydin H, Visintin P (2017) Extraction and analysis of bond-slip characteristics in deteriorated FRP-to-concrete joints using a mechanics-based approach. J Mater Civ Eng 29(6):04017013

24. Aydin H, Gravina RJ, Visintin P (2018) A partial-interaction approach for extracting FRP-to-concrete bond characteristics from environmentally loaded flexural tests. Compos Part B 132:214-228

25. Lu XZ, Teng JG, Ye LP, Jiang JJ (2005) Bond-slip models for FRP sheets/plates bonded to concrete. Eng Struct 27(6):920-937

26. Ko H, Sato $Y$ (2007) Bond stress-slip relationship between FRP sheet and concrete under cyclic load. J Compos Constr 11(4):419-426

27. Toutanji H, Han M, Ghorbel E (2012) Interfacial bond strength characteristics of FRP and RC substrate. J Compos Constr 16(1):35-46

28. Chen JF, Teng JG (2001) Anchorage strength models for FRP and steel plates bonded to concrete. J Struct Eng 127(7):784-791

29. Yao J, Teng JG, Chen JF (2005) Experimental study on FRP-toconcrete bonded joints. Compos Part B 36:99-113

30. Cao SY, Chen JF, Pan JW, Sun N (2007) ESPI measurement of bond-slip relationships of FRP-concrete interface. J Compos Constr 11:149-160

31. Seracino R, Raizal Saifulnaz MR, Oehlers DJ (2007) Generic debonding resistance of EB and NSM plate-to-concrete joints. J Compos Constr 1(62):62-70 https://doi.org/10.1061/ (ASCE) 1090-0268(2007)11

32. Zhang HW, Smith ST (2014) Numerical simulation of FRP-to-concrete interfaces incorporating frictional resistance of debonded plate. In: Smith ST (ed) 23rd Australasian conference on the Mechanics of Structures and Materials (ACMSM23). Byron Bay, Australia

33. Popovics S (1973) A numerical approach to the complete stressstrain curve of concrete. Cem Concr Res 3(5):583-599 
34. $\mathrm{ACl}$ (American Concrete Institute) (2005) Building code requirements for structural concrete. ACl-318-05, ACl Committee 318, Farmington Hills, MI

35. Ko H, Matthys S, Palmieri A, Sato Y (2014) Development of a simplified bond stress-slip model for bonded FRP-concrete interfaces. Constr Build Mater 68:142-157

36. Monti M, Renzelli M, Luciani P (2003) FRP adhesion in uncracked and cracked concrete zones. In: Proceedings of 6 th international symposium on FRP reinforcement for concrete structures. World Scientific Publications, Singapore, pp 183-192
37. Brosens K, Van Gemert D (1999) Anchorage design for externally bonded carbon fiber-reinforced polymer laminates. In: Proceedings of the FRPRCS-4, SP-188. ACl, pp 635-645

38. Nakaba K, Kanakubo T, Furuta T, Yoshizawa H (2001) Bond behavior between fiber-reinforced polymer laminates and concrete. ACl Struct J 98:359-367

Publisher's Note Springer Nature remains neutral with regard to jurisdictional claims in published maps and institutional affiliations. 